University of New Mexico

UNM Digital Repository

Long Term Ecological Research Network

Long Term Ecological Research (LTER)

1992

Guidelines and Sample Protocol for Sampling Forest Gaps

James R. Runkle

Follow this and additional works at: https://digitalrepository.unm.edu/lter_reports 
United States

Depariment of

Forest service

Pacific Norlhwest

Research Station

\section{Guidelines and Sample Protocol for Sampling Forest Gaps}

General Technical Repori

PNW-GTR-283

May 1992

UNS James R. Runkle

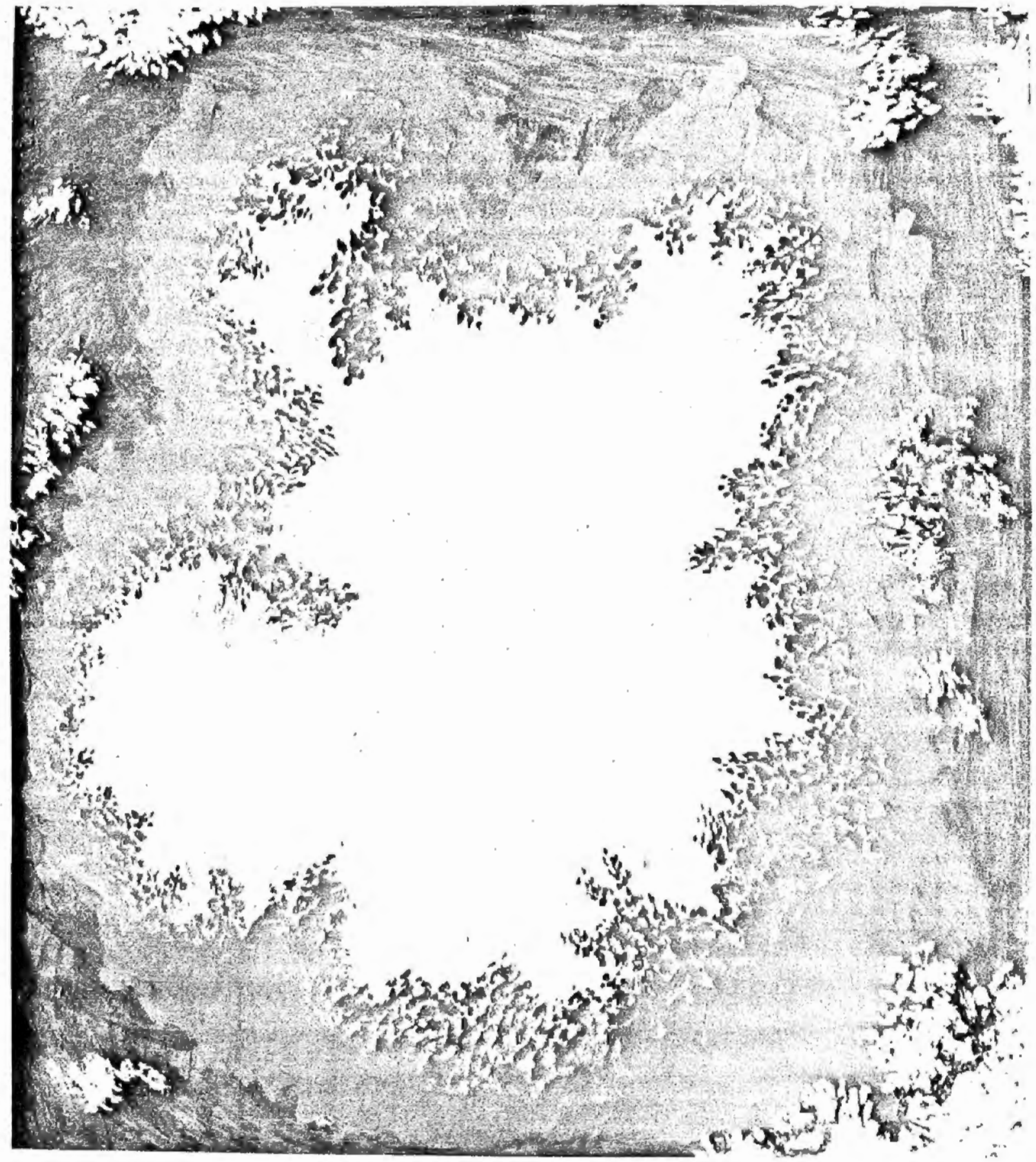



Sciences, Dayton, Ohio 45435.

This publication is the product of a series of technical meetings initiated and lacilitated by scientists Jerry Franklin and Thomas Spies of the USDA Forest Service, Pacific Northwest Research Station. 


\section{Abstract}

Contents
Runkle, James R. 1992. Guidelines and sample protocol for sampling forest gaps. Gen. Tech. Rep. PNW-GTR-283. Portland, OR: U.S. Department of Agriculture, Forest Service, Pacific Northwest Research Station. 44 p.

Comparative studies of forest structure and dynamics require standardized methods. A protocol for sampling forest canopy gaps is presented. Methods used in published gap studies are revlewed. The sample protocol will be useful In developing a broader understanding of forest structure and dynamics through comparative studies across different forest ecosystems.

Keywords: Forest structure, forest canoples, gap dynamlcs, heterogeneity, natural disturbance.

$\begin{array}{ll}1 & \text { Introduction } \\ 1 & \text { Background } \\ 2 & \text { Revlew of Published Gap Methods } \\ 2 & \text { What Is a Gap? } \\ 5 & \text { How To Sample for Gaps } \\ 8 & \text { What To Record About Gaps } \\ 16 & \text { A Protocol for Sampling Forest Gaps } \\ 16 & \text { What Is a Gap? } \\ 16 & \text { How To Sample for Gaps } \\ 16 & \text { What To Record About Gaps } \\ 18 & \text { Calculatlng Gap Propertles } \\ 19 & \text { Example } \\ 29 & \text { Acknowledgments } \\ 29 & \text { Literature Clted } \\ 32 & \text { Appendix 1: Partlclpants In Gap and Related Workshops } \\ 33 & \text { Appendlx 2: Calculatlon of Gap Area as a Polygon } \\ 34 & \text { Appendlx 3: Sampling Efflclencles of Belt and Line Transects } \\ 35 & \text { Appendlx 4: Blank Data Forms }\end{array}$

1 Background

Revlew of Published Gap Methods

What is a Gap?

Sample for Gaps

16 What is a Gap?

16 How To Sample for Gaps

16 What To Record About Gaps

29 Acknowledgments

Literature Clted

32 Appendix 1: Particlpants in Gap and Related Workshops

Appendlx 2: Calculation of Gap Area as a Polygon

35 Appendlx 4: Blank Data Forms 
Introduction

Background
The dynamic nature of forest ecosystems has been and is an Important area of research. Tree establishment, growth, and mortality processes and patterns are of special concern. One Issue is the different perspectives of loggers and foresters on the use of a crop of trees. Loggers are thought to be concerned with only the existing crop of trees. Foresters, however, are thought to be concerned about harvesting the existing crop so that a new forest of desirable species composition can be established quickly.

In many natural forests, replacement of trees usually occurs on a tree-by-tree basis In localized sites referred to as gaps. Comparisons of this phenomenon in different locations are interesting and worthwhile. Useful comparisons among forests include (1) the rates at which gaps form, (2) the total area occupled by gaps of different ages, (3) the size distribution at which gaps form, and (4) the speed and mechanisms of gap closures. Such comparative ecosystem studies are especially valuable in general understanding and predictlve abilities. One such approach is the integration of studies over the diverse sites represented in the Long Term Ecological Research (LTER) network.

A generally accepted definition or sampling protocol for gaps is needed for such comparative studies. Gap phenomena are familiar to many researchers, but definitions precise enough to be reproducible are not. This paper provides such a definition and sampling protocol, which will facilitate comparisons among different forest ecosystems. The exact procedure for any one study depends on the specific purposes and circumstances involved; this paper therefore will discuss some of the main variations in sampling procedure given in the literature. One specific protocol thought to be satIsfactory for studies is provided, however, for people beginning a study.

This report is organized as follows. First, a review of published methods demonstrates techniques used, Identifles a preferred set, and considers circumstances under which devlations from the given protocol may be appropriate. Second, a shortened protocol is presented that is sultable for reproduction for field workers; this includes sample data sheets that can be photocopied. Equations are provided to convert raw data Into estimates of forest properties; examples are given of how to fill out the forms and calcutate the fraction of land area in gaps. Flnally, appendices provide specific information on calculation of gap area based on a selected definition and on evaluation of differences between the results of line and one type of strip (belt) transects.

A workshop on forest gaps was held at the Harvard Forest in 1986 (Christensen and Franklin 1987). The participants stated that important advances in the understanding of ecosystem processes could be achleved through cross-system comparisons. Com. parisons of gap processes In forest systems had been limited by a lack of standardIzed methods for sampling and describing gaps. No single sampling protocol could be Ideal for all forests or for all questions about gaps, because forests differ greatly in their structure and gap dynamics. Nonetheless, the workshop participants thought it Important to devise a protocol for sampling forest gaps that could be tested in several forest systems and revised before comparative studies began.

A first version of the protocol was prepared by Robert K. Peet based on discussions at that workshop and field tested by several researchers: Ken Lertzman in old conifer stands in British Columbia, Robert Peet in Piedmont forests in North Carolina, James Runkle in an oak-sugar maple stand In Ohio, and Thomas Spies in conifer forests in Oregon. This initial testing was discussed October 23-25, 1986, at a workshop on permanent plot studies sponsored by the Institute of Ecosystem Studies and at the 
Review of Published Gap Methods

What is a Gap?
Cary Arboretum. James R. Runkle revised the protocol based on those comments. The revised protocol was further critiqued by participants in a second workshop on forest gaps held at the H.J. Andrews Experimental Forest May 22-23, 1987. A second revision was reviewed and comments incorporated into this present version. Workshop participants are listed in appendix 1; without their efforts, this protocol would not be possible.

Research on forest regeneration and dynamics has often focused on the deaths of individual canopy trees and the processes by which they are replaced. Different terms have been proposed for sites during this transition period, that is, between the death of one dominant individual and the establishment of another. Foresters have used the term "opening" (Gysel 1951, Trimble and Tryon 1966, Tryon and Trimble 1969); French-oriented ecologists, "chablis" (Oldeman 1978); and English-speaking ecologists, "gap." The last term comes from the description of the forest cycle by Watt (1947), in which he defines the gap phase of the cycle as that "lo which regeneration is confined because it is excluded from other phases." Starting with Bray (1956), gap has been widely used for the physical location and vegetation assoclated with sites lacking a competitively dominant individual.

Although exact definitions for gap differ slightly, most agree in some ways (fig. 1). Gap refers to an area within the forest where the canopy (leaf height of tallest stems) is noticeably tower than in adjacent areas. Most researchers agree that to count as a gap, this lowering must be due to the death of a Jarge branch, a single tree, or a few trees. The simullaneous death of more than a few canopy trees is outside the range of most gap studies, belonging to studies of succession atter large-scale distumance or the replacement of whole stands rather than small areas within a stand. At the first workshop, gaps were defined as the death of from one-hall to 10 trees (Christensen and Franklin 1987). An alternate, upper limit is for the canopy height-gap diameter ratio to be equal to 1.0. This definilion has been found more appropriate for certain young coniferous forests in Oregon. ${ }^{1}$ For many forests, these two upper limits are about equal.

This definition of gaps as a product of disturbance works well for many forest types. In some forests, however, small areas are free of trees for very long periods due to soll, bedrock, or biological factors; for example, parasitic fungi or allelopathy produced by early establishing ferns and herbs (Horsley 1977a, 1977b). Whether these areas should be included as gaps is not clear and may depend on the specific research questions asked: they may resemble gaps in the composition, structure, and function of their biola but not In their dynamics.

Most definitions of gaps also restrict them to the areas directly under the canopy opening (the canopy gap of Runkle [1982]), although additional areas may sometimes be included (for example, the expanded gap of Runkle [1982] goes to the bases of canopy trees bordering the gap [fig. 2]). To describe the dynamics of the canopy, the former definition is sufficient. Additional areas may need to be sampled to adequately characterize the vegetational response and environmental effects.

Some researchers define gaps as openings larger than some minimum limit: for example, 10 square meters (Nakashizuka 1984), 20 square meters (Brokaw 1982), or 25 square meters (Veblen 1985). The first workshop set this limit indirectly, as

\footnotetext{
Personal communication. Thomas Spies. 1987. USDA

Forest Service, Paclific Northwest Fesearch Station, Corvallis, OR 97331.
} 


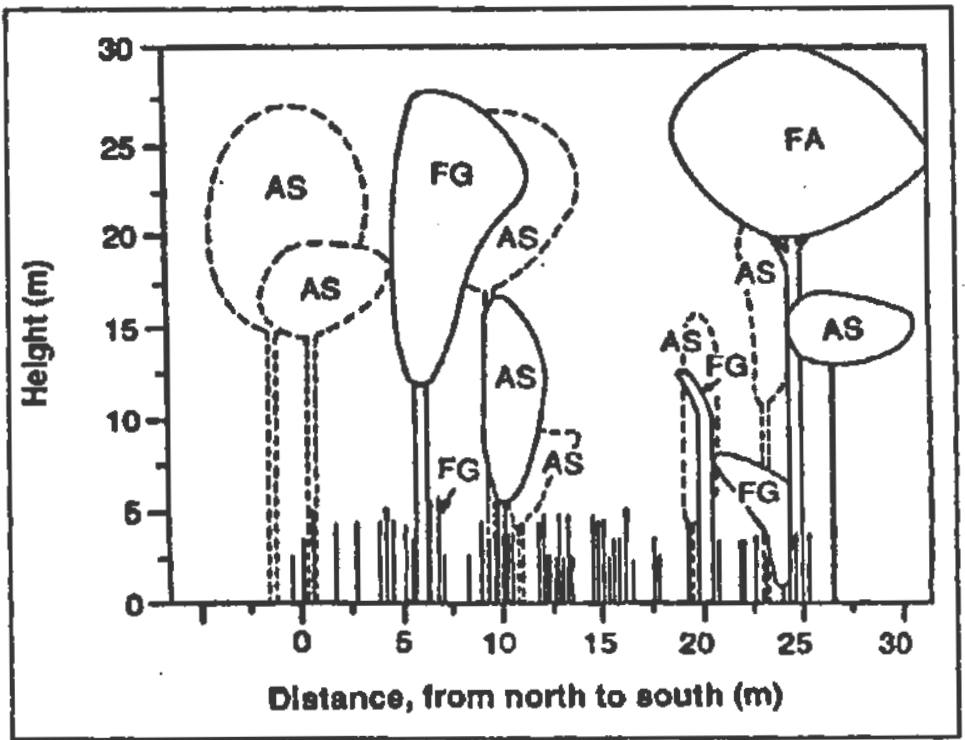

Figure 1-Canopy profile through a single-tree gap in Hueston Woods Nature Preserve, southwest Ohio. Transect width was 10 melers; trees toward the beck of the transect are sketched with dotted lines. Species codes are FA = Fraxinus americana, FG = Fagus grandifolia, AS = Acer saccharum. Note lall stump at horizontal distance $=20$ meters whose formation created the gap.

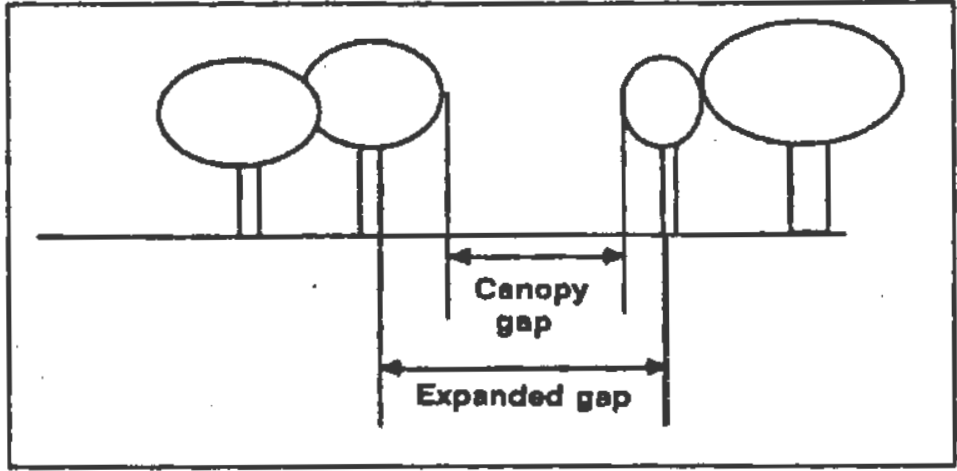

Figure 2-Gap defintions for canopy and expanded gaps.

one-half of a canopy tree. Other workers use only gaps created by more than one whole canopy tree (for example, Gysel 1951, Romme and Martin 1982, White and others 1985). Gaps can be small for two reasons: first, they may be created by the death of a small canopy tree or by one branch; second, they may be old, the remnants of larger openings almost closed by the lateral extension (branch) growth of canopy trees surrounding the gap. The distinction between these two types of small gaps is generally not considered when minimum gap sizes are given. Runkle (1982) included both kinds, but only if the canopy opening was not obscured by the regeneration.

Probably the most variable and arbitrary part of gap definitions is distinguishing when a gap merges with the background vegetation. Clearly, many gaps fill from below; that is, saplings within gaps grow steadily upward, gradually obscurring the 
distinctiveness of the gap. Runkle (1982) declares gaps closed when gap saplings prevent a ground observer from readily observing the canopy opening; he estimates that this will usually occur when saplings are 10-20 meters high in forests with a 30-35-meter-tall canopy. Nakashizuka and Numata (1982a) define gaps as areas with crowns <10 meters high, where normal canopy height is 20-30 meters. Nakashizuka (1984) uses 15 meters as the cutoff for forests with a 30-meter canopy. Veblen (1985) uses 15-20 meters with a 30-35-meter canopy. Naka (1982) used 15 meters as an upper limit for gap crown height. The first gap workshop proposed that gaps be defined as closed when regeneration within them was dominated by stems $>5$ centimeters diameter at breast height (d.b.h.); 5 -centimeter d.b.h. is the standard cutoff for saplings in the forestry literature. Because the relation between sapling height and d.b.h. depends somewhat on site conditions, using d.b.h. in the definition helps scale the definition for canopy height.

The precise cutoff depends on the questions asked, Including the size classes of special interest. Establishment of new trees is unlikely in areas of 10-meter-tall saplings. Changes in relative importance may still be taking place at that slage, however, which may be crucial in determining the eventual species dominants of the gap. Scientists interested primarily in regeneration will consider gaps to be closed before scientists interested in sapling dynamics or in average vegetation structure (gaps and nongaps).

Some research includes only gaps of recent origin, based on repeated surveys of the same area (for example, Brokaw 1985, Romme and Martin 1982). In such cases, the distinction between new gaps and background vegetation is clear enough that criteria based on sapling height are nejther needed nor given.

Gaps formed by several distinct episodes of tree mortality present another area where a decision must necessarly be arbitrary. There may be a causal though delayed connection between two disturbances, or they may be independent. Such repeat disturbances can be common, based on overall moderate disturbance rates and the large number of canopy trees that border small gaps (for example, Runkle and Yetter 1987). This factor increases in importance as the time required for gap closure lengthens. It is unclear which age of gap is more relevant; that is, the age since the first disturbance, when some of the taller saplings may have originated, or the age of last disturbance, which initlated the most recent period of growth and establishment. Most workers have probably combined the different sections of such a complex gap together as a single entity, albeit with some complications in its interpretation (for example, Runkle 1982). One approach to complex gaps (gaps of multiple origins) is to record them both as single entities and as subdivisions or sections corresponding to individual gap makers (trees whose whole or partial deaths create the gap) or events. Sections could be defined subjectively or related to some quantifiable variable, such as the relative basal area of each gap maker. If dividing the gap into differently aged sectors is too difficult or time consuming, it might be sufficient to estimate just the earliest and latest events. Again, this problem is minimized by sampling only recent gaps. 
One assumption basic to much gap research is that the distinction between gaps and the background vegetation is reasonably dlscrete. Such an approach may be inappropriate for some forest types in which the canopy is more generally open or In which canopy trees are widely spaced, such that the increases in light and soil moisture generally associated with gaps are spread more diffusely through the understory instead of being concentrated in discrete locations. Similarly, the definition of gaps may be difticult in multilayered forests, partlcularly when the species of the replacement tree does not achieve the height of the tallest canopy layer.

One addlitional fundamental decision is whether to deflne gaps by their structure or by a set elapsed time since their formatlon. Defining gaps by elapsed time has certain theoretical benefilts. Gap blith rates and initial size distributions can be calculated more preclsely. Accurate data are obtained on gaps that include large suppressed saplings or trees and whose environmental features promote rapid sapling growth. Unfortunately, defining gaps by structure is much easier and more objeclive. Gap age is often difficult to estimate accurately. Also, flnding gaps may be difflcult if tall saplings or subcanopy trees are present. A structural definition for gaps, however, should still be set so that virtually all recent ( $<5$ years or so) gaps are identifled and estlmates of gap blith rates are as accurate as possible.

Several different ways to sample for gaps have been used successfully. The most appropriate technlque depends on the speclitic questlons of a particular study and the nature of the forest. Some sampling techniques involve detalled observations of whole stands, such as complete gap surveys, measures of actual canopy height in a grid network, and aerial photographs. Other techniques involve taking subsamples of the stand by using line intersect sampling, strip (belt) transects, or some combination of the two.

Complete surveys - Complete surveys of small woods, otten including repeated visits, are possible. Romme and Martin (1982) used thls technique to sample a 104-hectare woods at monthly intervals for several years. This technique probably gives the most accurate values for rates of gap formation, gap size distribution, and repeated disturbance. It may take several years, however, to obtain sufficient data if relatlvely few gaps occur per year. It also may be difficult to accurately sample very small gaps; for example, those created by branch death (Romme and Martin sampled only gaps caused by at least one whole canopy tree). Other examples of this technlque are studies by Harcombe and Marks (1983), who recorded mortality of all stems $>4.5$ centimeters d.b.h. In a 4 -hectare plot, divlded into 20 - by 20 -meter sections, and Nakashizuka and Numata (1982a, 1982b), who used large intensive plots.

Actual canopy helght-Measurement of actual canopy helghts on a regular grid system throughout a stand is another technique for gap surveys. ${ }^{2}$ Such a mapped grid provides a more accurate view of varlation In canopy structure than a simple gapnongap dichotomy. It also clearly locates large gaps and glves a reasonable estimate of the fraction of land area in gaps as the proportion of grid points in gaps. This technique is most useful for small, intensively sampled woods, particularly in conjunction with permanent plot studies (Parker and others 1985).

\footnotetext{
2 Personal communication. George R. Parker. 1987.

Department of Forestry and Natural Resources, Purdue University, West Lafayette, IN 47907.
} 


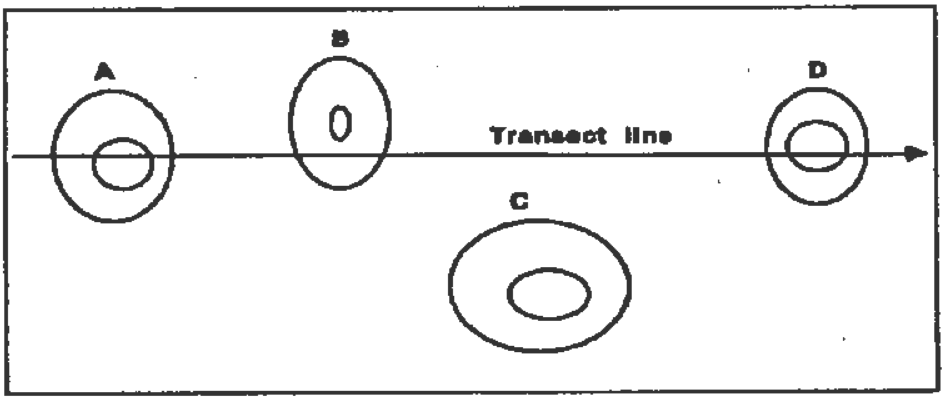

Figure 3- Line intersect sampling. Gaps are shown as concentric circles representing the canopy and expanded gap definitions. Gaps A and D would always be included in the sample because their canopy gaps are intersected. Gap $\mathrm{C}$ would nol be sampled because it is not intersected by the transect. Gap B could be sampled if the expended gap definition is used but would not contribute to estimates of the fraction of land in canopy gaps.

Aerial photography-Aerial photography has rarely been used in the study of gaps but could have great potential. Simultaneous readings of canopy height and ground surface could show the total range of conditions that exist. Bnunig's (1973) study of large lightning-caused gaps in Sarawak is a good example of the use of aerial photos taken several years apart to track the dynamics of a region.

Subsampling the stand-A random sample of the total population of gaps can be oblained by including only the gaps encountered abng transects. Several decisions must be made. First, will the sampling be conducted once or repeatedly? One-time samples (for example, Runkle 1982) typically include gaps of many ages; periodic sampling (for example, Brokaw 1985) typically records only gaps created during the last sample period and then follows these gaps through time. Of the two techniques, one-time samples yield a larger sample size of gaps in the same amount of field time and immediately include gaps of many ages, whereas periodic sampling gives more accurate estimates of initial gap sizes and vegetation and better quantifies the Incidence and effects of repeat disturbances. Periodic sampling requires access on a regular basis to the field site and some well-marked system of transects; for example, a foot trail network (for example, Brokaw 1982a).

A second decision to be made is how to measure distance. Ideally, transect distances and gap locations along transects are measured by using meter tapes. Although pacing distances is quicker and easier, especially for single investigators or in shrubby or dense forests, it is less accurate than taping.

Another pair of related decisions to be made are how wide a transect should be and which gaps, relative to their location on the transect, should be included in the sample. Depending on the sampling nule used to determine which gaps should be included, it might be necessary to correct the obtained gap size class frequency distribution tor sampling bias. The equations correcting for bias can be relerred to as estimators. Two techniques have been used most often in the field: (1) line transects which sample only gaps intersected by the line and (2) strip (beft) transects, which sample gaps for which a key point falls within the strip. These two sampling rules will be discussed in more detail below, as will an intermediate technique. 
LIne Intersect sampling-Runkle (1982, 1984), Veblen (1985), and White and others (1985) have used line intersects (1lg. 3). Gaps are included in the sample if they are intersected by a transect line established along some compass direction. The probability of a gap being sampled In such a system depends on its size: larger gaps are more likely to be Intersected than small ones. Estimators have been developed to offset this blas (De Vries 1974, De Vrles and Van Eljnsbergen 1973, Pickford and Hazard 1978, Runkle 1985). De Vrles (1974), for example, worked out the following estimators for circular objects: If a straight line (or transect) of length $L$ is run through a population of elements (for example, gaps) and if the transect intersects $n$ elements, then the expression,

$$
\theta(x)=\frac{1}{L} \sum_{j=1}^{n} \frac{x_{j}}{d l},
$$

Is an unblased estimator of the true mean quantity per unit area,

$$
x=\frac{1}{W L} \sum_{F=1}^{N} x,
$$

where $X_{j}$ is the true value of any characteristic (for example, gap area) of the th element (gap), dj is the diameter of the clrcular element, and $N$ is the (unknown) total number of randomly distributed elements within a rectangular area of size WL, W being an arbltrary width $>$ d. The variance of thls expression may be estimated as,

$$
\operatorname{var} \theta(x)=\left[\frac{1}{L}\right]^{2} \sum_{F=1}^{n}\left[\frac{x_{j}}{d_{i}}\right]^{2},
$$

Runkle (1985) used these expresslons for elliptically shaped gaps by estimating the diameter of gap | as,

$$
d=2 *(A / \hbar))^{0.5} \text {, }
$$

where $A_{j}$ is the area of the $j$ th gap Intersected by a transect.

To estlmate the fractlon of land area in gaps, use equation 4 and let $X_{j}=A_{j}$.

Therefore,

$$
\frac{X}{d)}=\frac{(\Pi+A)^{0.5}}{2} \text {. }
$$

Equation (5) can be substituted into equations (1) and (3) to estimate the mean and variance of the fraction of land area in gaps.

An alternate way of calculating the fraction of land area in gaps is to divide the transect distance in gaps by the total transect distance. Fortunately, these two ways of estimating the fraction of land area in gaps produce similar values (Runkle 1985).

Strlp transects using polnt crlterla for sampling gaps-Several researchers have identifled gaps by using strip transects (fig. 4). Brokaw (1982) used 20-meter widths. Nakashlzuka (1984) and Naka (1982) used 30-meter widths. Small gaps may be more easlly missed when wide transects are used but more gaps will be Included, espe-

clally small ones. The ease of gap recognition in different forest types may set the 


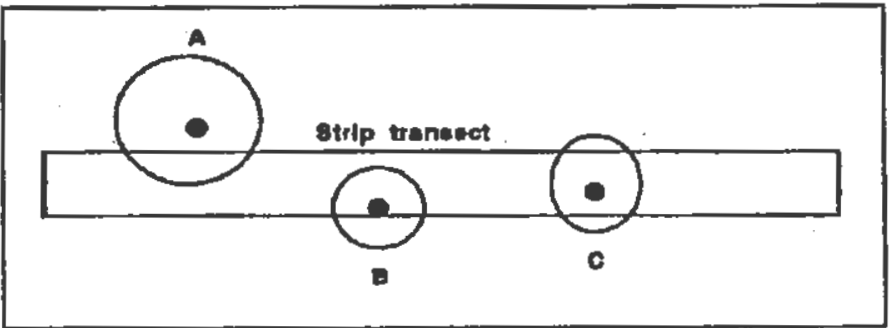

Figure 4-Suip transects using point criterla for sampling gaps. Gaps are shown as circles with a central dot indicating an objectively defined central point. If the dot is included in the transect, the gap is campled (gaps B and C); otherwise the gap is not sampled (gap A).

optimal balance between these limits. To use this method, it is necessary to decide which gaps wholly or partly in the strip will be included. One decision is to include gaps only if a single, specified point within the gap falls within the strip. Brokaw (1982) included gaps for which the center of the tree primarily responsible for causing the gap fell within his transect. Nakashizuka (1984) included gaps whose center fell within the strip. This technique is not biased toward large gaps: all gaps are equally likely to be sampled, and so corrections to the observed size distribution are not necessary. The fraction of land area in gaps is the sum of areas of all gaps sampled divided by the total area of the strip transect. One can expect gap areas of sampled gaps that lie outside the transect to compensate for areas within the transect of gaps whose centers lie outside the transect.

Strip transects using intersects as a crlterion for sampling gaps-To increase the number of gaps sampled, it is possible to combine the above two procedures to some extent. A strip transect could be used, but any gap intersected by the transect to any extent would be sampled. To my knowledge, this procedure has not been tried betore. The statistical properties of the results have not been examined. Appendix 3 analyzes the bias of this procedure for sampling large gaps. In general, this procedure would increase the number of gaps sampled, even for tairly small strip widths. The effect is more pronounced for small gaps than for large gaps.

All three transect sampling techniques lend themselves to sampling of nongap vegetation, such as the point-centered quarter method (Cottam and Curtis 1956; used in Runkle 1982) or complete lists of stems in smaller, enclosed (ṇested) belt transects (Nakashizuka 1984). Such information is useful in describing the background vegetation or matrix, thereby allowing comparisons of species regeneration in gaps and under the canopy (Runkte 1981) and in relocating gaps and transects after several years (Runkle 1984, Runkle and Yetter 1987).

What To Record About Gaps
Gap makers_-Gap makers are those trees that died and thus formed a gap (fig. 5). The species, d.b.h., original height, direction of fall if any (base to top), agent of death and type of damage (uprooting, partial uprooting, breakage with stump height, standing dead, and partial death) should be determined or estimated. Some minimum size for gap makers will need to be stipulated for the stand of irterest to separate faljen canopy trees from falien understory trees. Runkle (1982) found 25 centimeters d.b.h. worked well as a lower limit in several forests in Eastern North America: death of trees <25 centimeters d.b.h. rarely created openings in the canopy; deaths of larger trees usually did. A different lower limit may be required for other forests. 

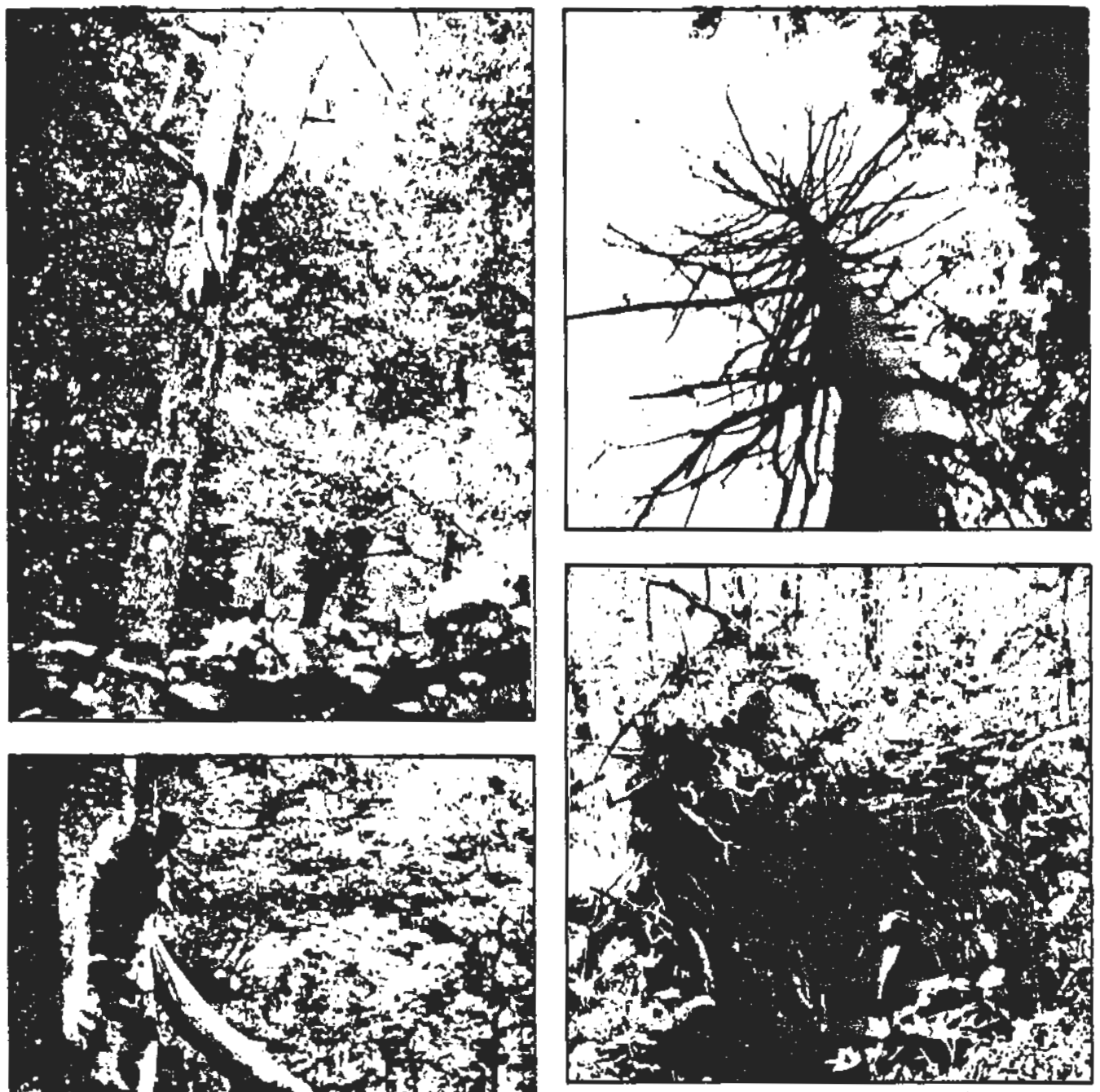

Figure 5-Gap makere showing several Injury typou. 
Gap size-Most gaps can be approximated by ellipsoidal shapes (fig. 6). These gaps are measured by tirst locating a pair of perpendicular lines in the gap such that the first is the longest straight line that will tit in the gap, and the second is the longest straight line that will fit in the gap with the constraint that the line is perpendicular to the first. Gap area often may be calculated directly from the lengths ot these two lines by using the formula for an ellipse (area $=\pi L W / 4$, where $L$ is the length of the longer line and $W$ is the length of the shorter line). Where the gap shape is too irregular to be approximated as an ellipse, the length of each line segment from the intersection to the gap edge may be recorded, starting with the longest and moving in a clockwise direction. Gap size is calculated as the sum of the four quarter ellipses determined by the line segments. The orientation of each gap will also be determined by recording the compass direction of the longest line segment.

In those unusual situations when gap shape is so irregular that an ellipsoldal approximation will grossly misrepresent the area of the gap, appropriate additional notes for later determination of gap area should be made.

An optional addition is to determine the area of the "expanded gap" (Runkle 1982). This is the area within a polygon constructed by drawing a line connecting the boles of all the trees whose crowns border the canopy opening (fig. 7). Field procedure consists of selecting a point near the center of the gap (preferably the intersection point previously used for estimating area) and measuring the distance and compass angle for a vector from the point to the bole of each marginal tree. This Intersection is recorded on the data sheet together with information on adjacent trees. It is also possible to use an elliptical measure of expanded gap similar to the measure used above for the canopy opening.

Gap microhabltats-Gaps consist of several identifiable microhabitats, including pit, mound, log, branch pile, bark pile, and remainder. The length and width of each of the first five categories can be measured. For some studies, it may be sufficient to estimate the percentage of gap area occupied by each microhabitat. The log can be approximated as a rectangle and the rest as ellipses. Log length should be measured withln the gap only. The remainder can be determined by subtraction. Not all microhabitats will occur in every gap. Where important, previously fallen logs should also be recorded.

Gap age-As mentioned earlier, the treatment of gap age (that is, time since gap formation) will difler with the exact purpose of the study. In some cases, it might be an intrinsic part of the gap detinition. Gaps may be limited explicitly to areas less than 1 , 5 , or 10 or more years old; older disturbances would be excluded from the study. In most cases, however, gaps are defined by their structure, with age simply being another descriptive varlable. Seven methods of determining gap age in order of priority (ease of use and accuracy) are (1) checking the leaf and bud conditions of the fallen trees; (2) determining release dates of saplings from bud scar counts (fig. 8) or radial increments (fig. 9); (3) aging rings on scar regrowth, sprout age, and changes in branch growth direction; (4) determining release dates of adjacent trees; (5) doing dendrochronology on the dead tree; (6) aging seedlings in the gap; and (7) using the decay state of the stem of the gap maker. 


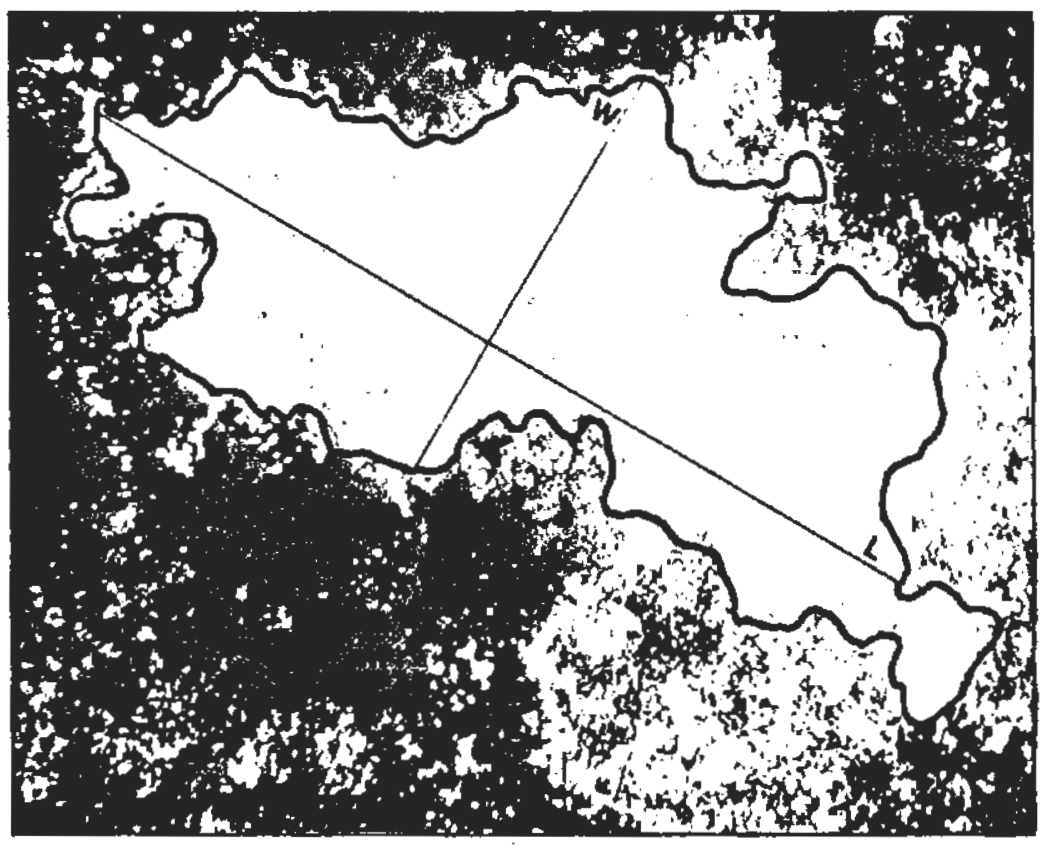

A



Figure 6-Fitting axes ( $L=$ length, $W=$ width) to the canopy opening. 


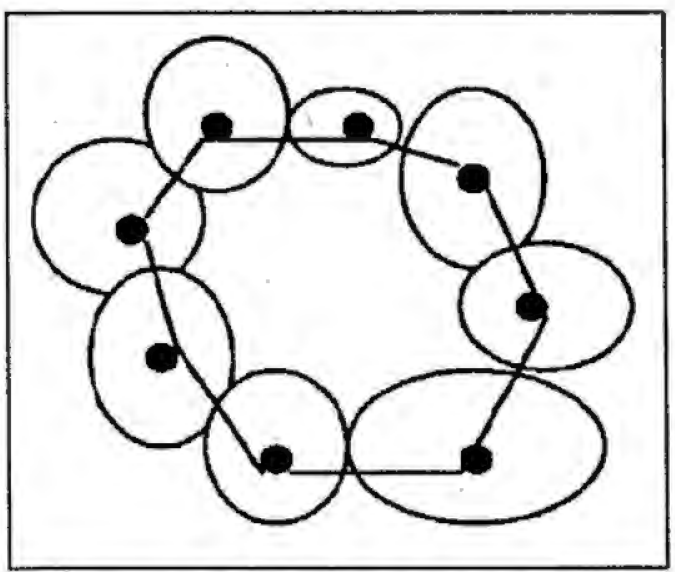

Figure 7-Expanded gap showing polygon constructed by drawing a line connecting the bases (dots) of canopy trees bordering the gap (tree crowns are shown).

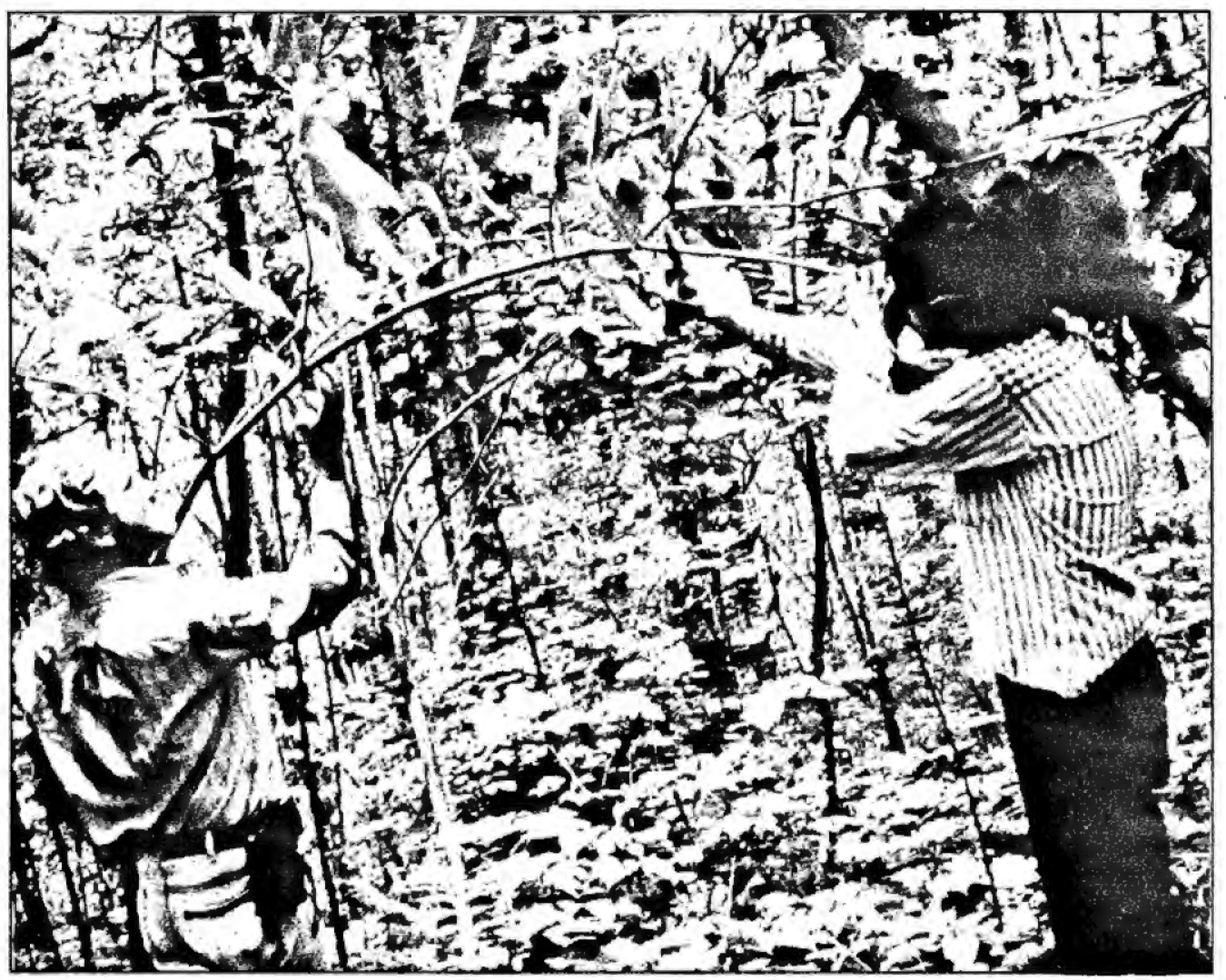

Figure B-Use of bud scars to indicate gap age. Between the thumb and fingers of Todd Yetter (on left) is 1 year of growth. Between his fingers and those of Matt O'Brian (on right) is next year of growth. This large increase indicales the origin of the gap nearby. 
Towerd troe center

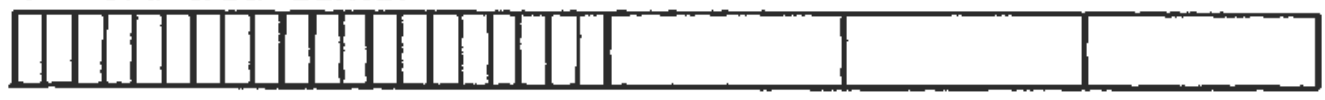

Figure o-Use of increment cores to Indicate gap age: in this case the dlstance between annual rings showed a sharp increase 3 years ago due to gap lomation.

Adjacent forest-Adjacent trees are those with crowns bordering the gap. The species of each of these trees is recorded and d.b.h. estimated to the nearest 5 or 10 centimeters (less precise d.b.h. estimates are justifled for some forest types). Estimation of d.b.h. allows species and slze to be recorded from the center of the gap without having to visit each tree. Also, the average height of the canopy adjacent to the gap is estimated. The height of the base of the canopy also is recorded; that measure can help determine the extent to which light extends under the canopy adjacent to the gap. Optionally, It is useful to measure the length of their crown extension into the gap for some of these trees. If this can be measured along a readily reidentified direction, resurveys will provide a useful estlmate of crown growth rates (Runkle and Yetter 1987).

Gap site characterlzatlon-The site of the gap is characterized in terms of slope (usually expressed as percent), aspect, elevation, topographic position (scale of 1-5). exposure to wind, and typical soll conditions. The topographic scale is 1 for valley bottoms, 2 for concave lower slopes, 3 for midslopes, 4 for convex upper slopes, and 5 for ridges.

Gap aperture-Gap aperture is an easlly measured and important index to the significance of gaps developed by Lawton and Putz (1988) (fig. 10). It is obtained by measuring the arcs of sky visible from gap center the intersection of the major and minor axes) along both axes and averaging them. It thus measures gap canopy openness and scales the size of the gap by the heights of the surrounding canopy trees. Measurements are taken at 1.5 meters high. Further work is needed to tell whether nonthsouth and east-west measures also would be useful.

Alternative indices of canopy openness are to measure the fraction of sky visible or to relate canopy openness to latitude, slope, and aspect. Easily used and calculated Indices of this type are still not available, however.

Canopy openness can be characterized by using fisheye photography, which might also be useful for long-term studies. Stewart (1986) used such photographs to assess differences ln total difluse and direct radiation at a height of 1 meter. He calculated the percentage of direct potential radlation by computing the percentage Intercept of visible sky along the tracks of the sun. A problem with using this technique is that the outcome will differ with the height of the camera. It might be hard to relate the results at a height of 1 meter to saplings that are substantially taller. Also, the sunlight avallable to taller saplings may be obscured by shorter saplings shading the camera. This technique still can be useful, however, in quantifying the relative light availability at different points in the gap.

Vegetation withIn the gap-Vegetation sampling within gaps depends on the nature of the forest study site and the objectives of the research. The simplest procedure is that of Barden (1979) and White and others (1985). They deal primarily with patterns of canopy replacement; that is, which species is most likely to replace which other species in a group. They try to identify, for gaps caused by single canopy trees, the 


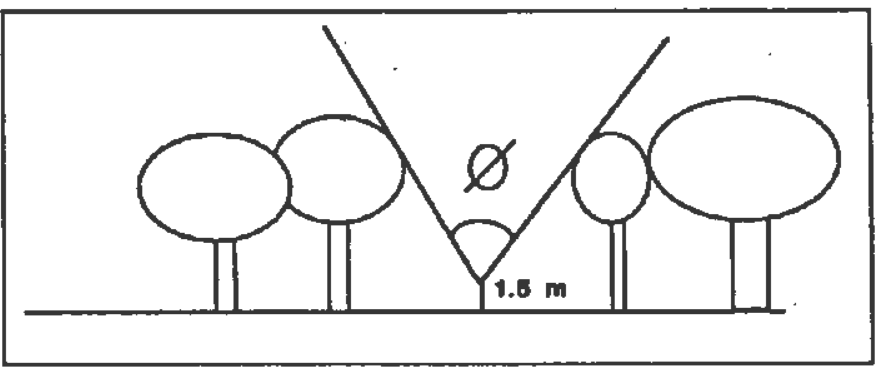

Figure 10-Measurement of gap aperture (angle $\theta$ ).

one sapling most likely to reach that canopy position. These probable replacement trees are taller and broader in crown diameter than other trees in the gap. Replacement individuals were identified in 95 gaps out of 103 gaps in a southern Appalachian cove forest (Barden 1979). This procedure seems most efficient when defining a replacement tree is the objective. Even where more complete descriptions of gap vegetation are required, it is worthwhile for gap researchers to identify the most likely replacement trees.

A second vegetation measurement technique is to use standard plot sizes, usually circular in shape, centered on the gap maker. Ehrenfeld (1980) studied gaps caused by gypsy moth defoliation in oak forests in New Jersey. Her plots consisted of two intersecting line transects 15.15 meters long, centered on (a) single dead oaks, (b) the central oak in clusters of $\geq 5$ dead oaks, and (c) healthy oaks. Huenneke (1983) used circular plots of 250 square meters centered on dead elms. Parker and others (1985), looking at a stand mapped in 1926 and 1976, counted as ingrowth (gapreplacing individuals) trees not present in 1926 but $>10$ centimeters d.b.h. in 1976 and $<5$ meters from a dominant or codominant tree that had died since 1926. Stewart (1986) also used a set plot size ( 10 by 10 meters) but subjectively sited the plot in patches of seedlings and saplings. These plots were compared to plots of the same size located under relatively closed canopy. The advantages of these techniques are that they are easier to lay out in the field, area is known exactly (instead of being estimated as an ellipse), and the data analysis is probably easier. On the other hand, gaps differ in size, and vegetational response is at least somewhat dependent on gap size, so a plot of a set area may miss some important information. Also, in small gaps, part of the plot will fall under the adjacent closed canopy; in large gaps, important components of the regeneration may be missed. For some sites, however, where gaps are all about the same size, this technique may be appropnate.

A third technique is to measure only saplings present under the canopy opening. Gysel (1951) and Minckler and Woerheide (1965) used this technique for small openings created by cutting. Brokaw (1985) used this method for his intensive study of tropical gaps. This technique has at least two virtues: it is consistent with the generally accepted gap definition, and it measures the area most likely to be affected by changes in environment associated with the gap. There are problems with this technique, however. Particularly at higher latitudes, the impact of gaps is often offset from gap center; the maximum vegetation response may occur under the neighboring canopy rather than directly under the canopy opening (Canham and others 1990). Gaps (canopy openings) gradually change in size and shape over time as the branches of bordering canopy trees grow into the gap; therefore, whether or not specific saplings should be included in gaps changes over time. For new gaps, this is 
not a major problem If gaps are defined as the canopy opening existing during gap creation. For older gaps, it raises the question, "Are gaps defined as the original openings or as present openings?" If the former, "How can the exact Initial boundaries be best determined?" Another problem is the extra field time necessary to determine for each borderline sapling whether it is under some canopy branch.

To deal with these problems, Runkle (1982) and Veblen (1985) measured vegetation in expanded gaps, deflned as areas consisting of the canopy gap plus the adjacent area extending to the bases of canopy trees surrounding the canopy gap. The main virtues of this technique are that it is easier to determine which saplings should be included, it is more stable over time, and it better measures the complete vegetation response to the gap. A problem with this technique is that lts measures of vegetation dilute the relatively small area most directly aftected by the gap with a larger area possibly showing only marginal or no response. Also, it is uncertain how often vegetation not found directly under a canopy opening can curve sutficiently to fill that opening. Individual trees unable to fill a glven gap may still benefit from it through enhanced growth and therefore better chances of filling subsequent gaps closer to their specific locatlon.

Within the area chosen, the easiest way to record individual stems is to compile lists, by species and size class, of each stem in the desired size classes. This technique has some problems if the gap is to be revisited later and exact estlmates of montality and ingrowth are desired. Knowing whether or not borderline Individuals were sampled before can also be a problem. Much more precision is possible if individual stems are mapped or individually tagged, and gaps are revisited (for example, Brokaw 1985). Doing so is time consuming and may not be worthwhlle if an extensive sample (large sample slze) is desired, however. A posslble compromise may be to make lists but underline or otherwise mark borderline indivlduals so that matching individual stems on a return visit is easier. The position of stems (central, near border of the canopy gap, and near border of the expanded gap) is also worth noting.

There is no general agreement on what size classes of stems to include or what ex. actly to record about each one. Gysel (1951), Runkle (1982), and Brokaw (1985) recorded all stems $\geq 1$ meter high; Nakashizuka and Numata (1982a) and Veblen (1985) recorded stems $\geq 2$ meters high; others have Included only one or a few of the largest stems. Most researchers have measured d.b.h. Height is also useful. Sapiling injuries, apparently sustained at the time of treefall, are sometimes recorded. Sapling substrate (for example, pit, mound, new or old fallen stem) is sometimes recorded. It is unclear how best to measure and analyze multiple stems from the same individual; for example, one broken of during gap formation, one naturally produclng such shoots (such as white basswood [Tilla heterophylla Vent.]), or one typically growing as clusters of stems (such as several understory shrubs). Herbs rarely have been sampled in gaps (but see Moore and Vankat 1986). Measuremerits of the last year, or several years, of height growth of saplings in the gap may be useful (Yetter and Rurkle 1986) for calculatlng rates of gap closure.

Concfusion-Many different techniques of sampling gaps have been proposed and used. This variation is justified by the diversity of questions asked and forests studied; however, this variation makes it harder to compare gap-dominated disturbance regimes from different forest types or regions. To facilitate such comparisons, one spe. cific protocol is outlined in the following section that may be appropriate for several diverse forest ecosystems. 


\section{A Protocol for Sampling Forest Gaps}

What Is a Gap?

How To Sample for Gaps

What To Record About Gaps
The following protocol for sampling forest gaps is recommended for several forests and research questions. Some modifications of these procedures may be necessary for particular studles. They are meant to be appropriate, however, for many possible conditions.

A gap is defined as follows: It is formed by the death (absence from the canopy) of at least one-half of a tree. The largest gap is created by the death of 10 canopy trees or has a ratio of canopy height to gap diameter equal to 1.0 , whichever is larger for the torest studied. When sampling, the resulting hole in the canopy must be deep enough to expose to the sky the crowns of stems that otherwise would be in the understory. Gaps close when replacement sterns reach a height indistinguishable from that of the surrounding closed forest. The edges of the gap are defined by a vertical projection of the canopy leaves of trees adjacent to the gap.

Line transects should be located randomly in a forest area with relatively homogeneous site conditions. The location on transects of the start and stop of each intersected gap are recorded (appendix 4). Specific data (indicated below) are recorded for each intersected gap (appendix 4). One data sheet should be prepared for transect information such as the exact starting location, compass direction of the transect, distances from the beginning of the transect at which gaps start and stop, and locations of other notable teatures (for example, trails, fallen logs, and streams). Location of point centered quarter-points can also be listed, it such are taken, to characterize canopy composition and to aid in locating the transect again later. Distance along the transect should be measured in meters by using meter tapes. Two options to increase the number of gaps included in the study are (1) to include gaps found within a certain distance of the transect line and (2) to include gaps whose expanded gaps (see below) are intersected by the transect, even if the gap defined by the canopy opening is not.

Gap orientation may be influenced by topography, for example, on areas of steep slopes, the long axes of gaps may be most commonly oriented downslope. In such forests, it may be necessary to run transects both across and up and down slopes.

Gap makers-Gap makers are those trees that formed the gap by their death. The species, d.b.h., orlginal height, direction of fall if any (base to top), agent of death, and type of damage (uprooting, partial uprooting, breakage with stump height, standing dead, partial death) are measured or estimated. A minimum size for gap makers will need to be determined tor the stand of interest to separate fallen canopy trees from fallen understory trees. A size of 25 centimeters d.b.h. is proposed as a standard, at least for forests in Eastern North America (Runkle 1982).

Gap size-Many gaps can be approximated by ellipsoidal shapes. These gaps are measured by first locating a pair of perpendicular lines in the gap such that the tirst is the longest straight line that will fit in the gap, and the second is the longest straight line that will fit in the gap with the constraint that the line is perpendicular to the first. Gap area often may be calculated directly from the lengths of these two lines, fitted into the formula for an ellipse (area $=\pi \mathrm{LW} / 4$, where $\mathrm{L}$ is the length of the longer line and $W$ is the length of the shorter line. Where the gap shape is more irregular, the length of each line segment from the intersection to the gap edge is recorded starting with the longest and moving in a clockwise direction. Gap size is calculated as the 
sum of the four quarter ellipses determined by the line segments. The orientation of each gap will also be determined by recording the compass direction of the longest line segment. On steep slopes where horizontal areas may be desired, the slope angle of each line segment should be recorded.

Where gap shape is too Irregular to be characterized as an ellipse, an alternate approximation is approprlate. Distances from gap center to edge are measured in at least the eight main compass directions, and the area of the resultant polygon is calculated directly.

In those unusual situations where gap shape is sufficiently irregular (that is, both of the above approximations will grossly misrepresent the area of the gap), the researcher is encouraged to make appropriate additional notes for later determination of gap area.

An optional addition is to determine the area of the "expanded gap" (Runkle 1982). This is the area within a polygon constructed by drawing a line connecting the boles of all the trees whose crowns border the gap (canopy opening). Field procedure consists of selecting a point near the center of the gap (preferably the intersection point previously used for estimating area) and measuring the distance and compass angle for a vector from the point to the bole of each marginal tre $\theta$. Use of an optical rangefinder may facilitate this procedure. A computer algorithm for computing gap area from such measurements is given in appendix 2 ,

Gap microhabitats - Gaps consist of several identifiable microhabitats: pit, mound, log, branch pile, bark pile, and remainder. The length and width of each representative of the first five categories caused by events creating the present gap are measured. The $\log$ is approximated as a rectangle and the others as ellipses. Log length is measured only within the gap. The remainder is determined by subtraction. Not all microhabitats will occur in every gap. Where important, previously fallen logs also are recorded.

Gap age-The treatment of gap age (that is, time since gap formation) differs with the exact nature of the study. In some cases, it might be an Intrinsic part of the gap definition. Gaps may be defined as less than $1,5,10$ or more years old; in such a case, older disturbances are excluded from the study. Gaps are often defined by their structure, however, and age is simply one more descriptive variable. The ability to age gaps helps determine which gaps are used in calculating gap-formation rates and forest turnover tlmes. Several different features can be used to determine gap age and are listed in order of priority (ease of use and accuracy): (1) the leaf and bud condition of fallen trees; (2) release dates of saplings from bud scar counls or radial increments; (3) ages of rings on scar regrowth, sprout age, and changes in branch growth direction; (4) release dates of adjacent trees; (5) dendrochronology of the dead tree; (6) ages of seedlings in the gap; and (7) decay state of the gap maker.

Some gaps are formed by several different episodes of tree mortality. Where possible, these gaps are subdivided into sections of different ages. Where this procedure is not practical, the gap will be treated as a single gap of the age of the most recent major tree mortality event. The fraction of the total gap area affected by this most recent. event should be estimated, perhaps by using the fraction of gap-maker basal area associated with the most recent mortality event. Alternatively, the dates of the earliest and most recent events can be recorded. 
Calculating Gap Properties
Adjacent forest-Adjacent trees are those whose crowns border the gap. The species of each of these trees are recorded and the d.b.h. estimated to the nearest 5 or 10 centimeters (less precise d.b.h. estimates are justified for some forest types). Estimation of d.b.h. allows the worker to record species and size from the center of the gap without necessitating a visit to each tree. Also, the average height of the canopy adjacent to the gap is estimated, though not for individual trees. The height to the bottom of the canopy also is estimated. Optionally, for some of these trees it may be useful to measure the length of their crown extension into the gap. If this can be measured along a readily reidentified direction, it may provide a useful estimate of crown growth rates, in conjunction with later resurveys.

Site characterization-The site of the gap is characterized in terms of longitude, latitude, slope, aspect, elevation, topographic position (scale of 1-5), exposure to wind, and typical soil conditions. The topographic scale is set equal to 1 for valley bottoms, 2 for concave lower slopes, 3 for midslopes, 4 for convex upper slopes, and 5 for ridges.

Gap aperture-This optional parameter is measured from gap center (the intersection of the major and minor axes) as the average of arcs of sky visible along both axes. It thus measures gap canopy openness scaling the size of the gap by the heights of the surrounding canopy trees. Measurements are taken at 1.5 meters high.

Vegetatlon with the gap-Within each gap, one or possibly more probable replacement trees are noted. These are the stems judged most likely by the researcher to reach the canopy because of their location, height, canopy spread, and health.

Stems of potential canopy trees at least 1 meter high are measured in 2-centimeter d.b.h. and in 2-meter height classes. As an option, stems can be measured directly under the canopy opening and also in the expanded gap. This option is particularly suggested for forests in higher latitudes, where light enters the gap at an angle less than perpendicular and so influences saplings under the surrounding canopy. If this option is used, special notes are made of stems (1) occurring in the canopy gap but not in the expanded gap and (2) occurring near the borders of the gap. The former should usually emphasize the main gap vegetation response. The latter will be useful if the gap is resampled and the former status (in or out of the gap) of individual border saplings becomes of interest.

The data collected by using the protocol outlined above obviously can be used to calculate many items of interest for gap dynamics. Many of these, for which comparisons among forest types might be especially profitable, are given below.

Percentage of total land area in gaps =

$$
\text { transect distance in gaps } \times 100 \% \text {, }
$$$$
\text { total transect distant }
$$

Percentage of total land area in gaps of specific size or age classes $=$

$$
\frac{\text { transect distance in gaps of specificed class } \times 100 \% \text {, }}{\text { total transect distance }}
$$

Gap formation rate $=$ percentage of total land area in gaps

$$
\text { sn years old divided by } n \text {, }
$$




\section{Example}

where $n$ m number of years for which a complete sample of gaps is obtained.

Tumover time ("turnover rate") = (Gap formation rate) ${ }^{-t}$.

For gap size frequency distributions as a percentage of the number of gaps rather than the area occupled by gaps, correction factors may need to be applied. depending on the sampling procedure used.

To show how to use the data sheets, I have modified some of the field data taken in a survey of gaps conducted by Stewart and Rose ${ }^{3}$ (table 1). The stand sampled was in a mountainous section of the South Island of New Zealand. The stand itself is a relatively flat terrace dominated almost entirely by red beech (Nothofagus fusca (Hook. f.) Oerst.) and silver beech ( $N$. menzlesï (Hook. f.) Oerst.).

Probable replacement trees in this study were identified as the tallest saplings $<20$ meters tall in each quadrant of the gap.

For the first 120 meters of the transect, the percentage of total land area in gaps can be calculated. By using the relative distance method (equation 6), expanded gaps make up 31 of 120 meters or 26 percent of the total area. Canopy gaps make up 20 of 120 meters or 17 percent of the total area. By using the line intersect method (equations 1 and 5) and the actual gap dimensions for gaps 1 and 2, the following values are derived:

E (gap area per land area)

$$
\begin{aligned}
& =\frac{1}{120} \Sigma \frac{\sqrt{\Pi \bar{A}}}{2}=\frac{1}{120} \times \frac{\Pi}{4} \Sigma \sqrt{L W} \\
& =\frac{\Pi}{480}(\sqrt{20 \times 17}+\sqrt{21 \times 14})=23 \% \text { for } E G \\
& =\frac{\Pi}{480}(\sqrt{14 \times 11.5}+\sqrt{11 \times 10})=15 \% \text { for } C G
\end{aligned}
$$

where $A$ m gap area, estlmated from gap length $(L)$ and width $(W, E G=$ expanded gap, and $C G$ a canopy gap.

The two technlques thus give similar results, even for such a small data set. Larger data sets show even closer agreement (Runkle 1985).

\footnotetext{
${ }^{3}$ Personal communication. Glenn H. Stewert and Allen Rose. 1989, Forest Research institule, Box 31-011, Christchurch, Now Zealand.
} 
Table 1-Example of fleld data collected in a survey of gaps from New Zealand

TRANSECT DATA

$$
\text { p. } 1 \text { of } 9
$$

Observers: _ G. Stewart, A. Rose Date $07 / \mathrm{Jan} / 1988$

S1te: Rough Creek

Transect number: $\quad 1$ Longltude: $172^{\circ} 13^{\prime} \mathrm{E}$ Latitude: $42^{\circ} 20^{\prime} \mathrm{S}$

Inftial compass bearing corrected for declination: $260^{\circ}$

Starting location description:

20 m from road across from parking area west of Rough Creek bridge. Marked with red marker nafled to $62 \mathrm{~cm}$ d.b.h. red beech.

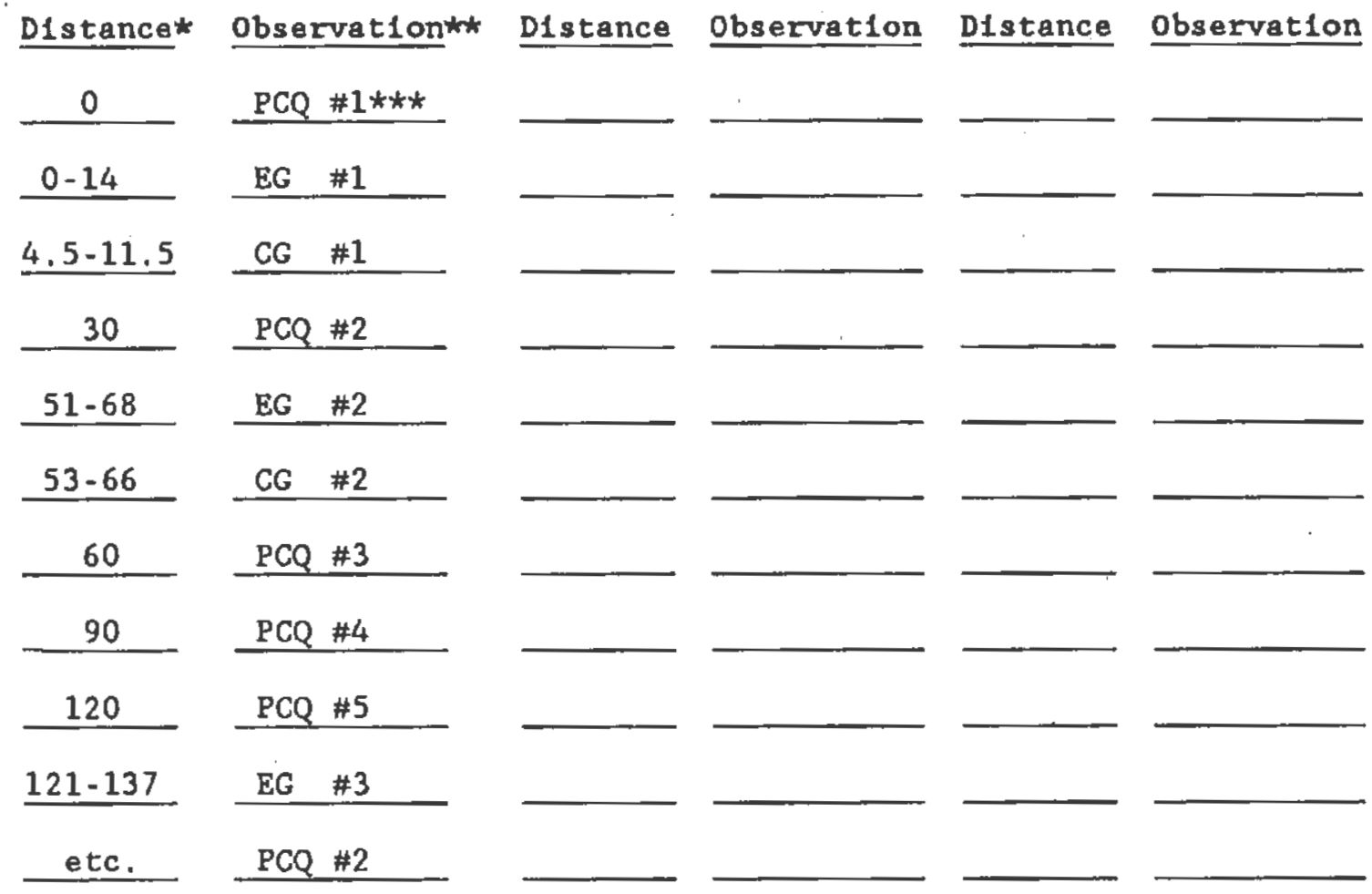

* In meters from starting position, using a tape.

** For example, start gap, end gap, tralls, fallen logs, streams, change compass direction, establish a point-centered quarter point, etc. *** PCQ - polnt-centered quarter polnt, CG - canopy gap, EG - expanded gap. 
Table 1-(continued)

GAP DATA

p. 2 of 9

Observers:

G. Stevart, A. Rose

Date $\quad 07 / \mathrm{Jan} / 1988$

site: Rough Croek

Transect number:

1

Gap number:

1

sketch and generel commente:

COriginal Direction**

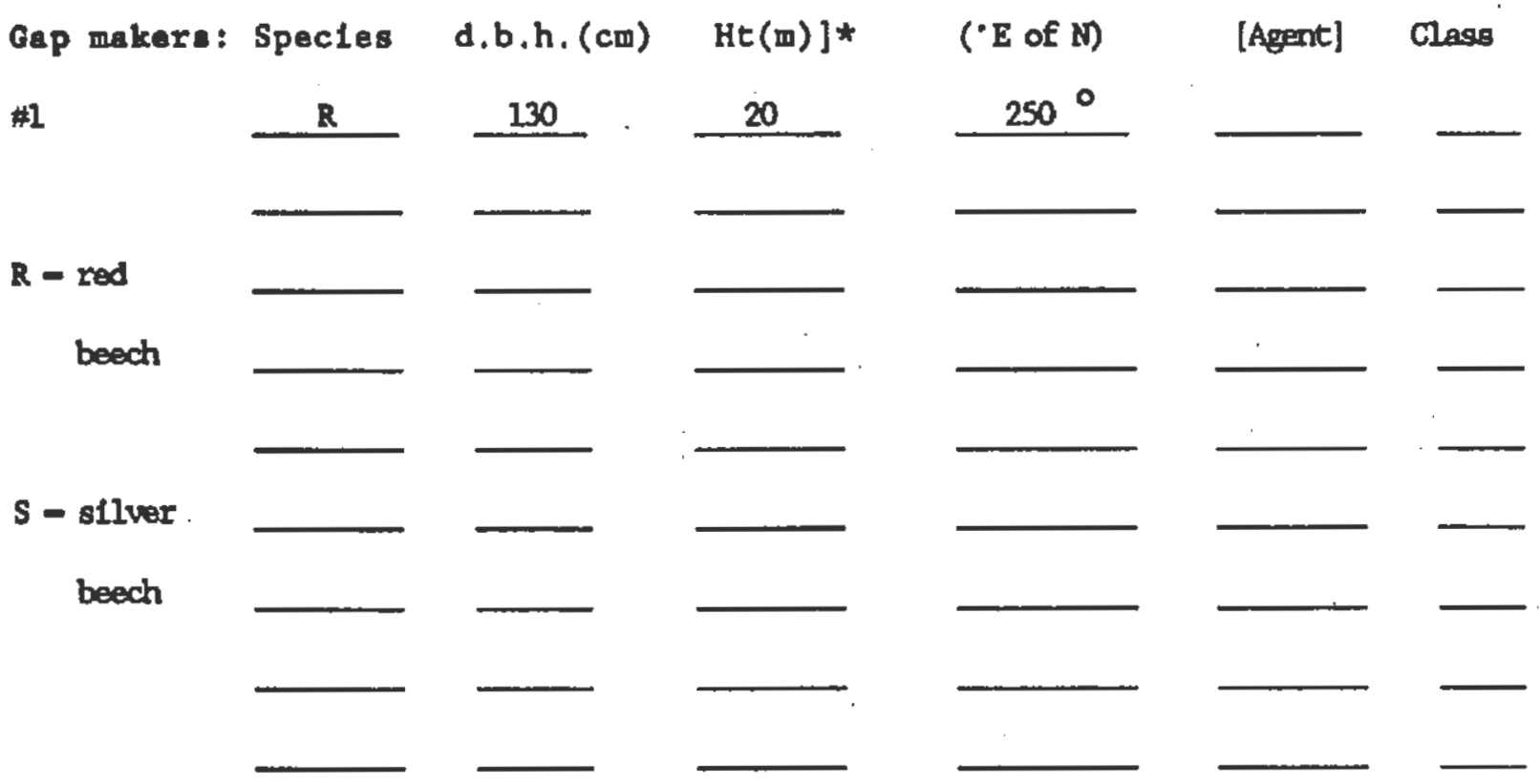

Grases: 1 - Uprooted; 2 - Partly uprooted; $3-$ Broken (stam ht);

4 - Standing dead; 5 - Limb dead or broken.

S1ze: Lengthe of 1 ine segments in moters, longest first and moving cloclawise, or other system (describe).

EG lengh $\quad$ ES with $\infty$ length $\quad \infty$ width

1. $20 \quad$ 2. $17 \quad$ 3. 14 4. 11.5

Campass direction of longest segment $15^{\circ}$

Average helght of dominent saplings in gep $3 \mathrm{~m}$ 
Table 1-(continued)

P. 3 of 9

[Land Glassification:**;] length $\mathrm{x}$ width measurements

Total

PAt

Hound

$\log$

Branches

Bark pile

Age: Select first avallable method.

1. Gap makar bud or leaf condition

old

2. Sepling release sges Core \#4, Core \#5,

method of decemination - bud scales / radtal increment.

3. Scars/demage/recovery $\cdot$ ' $+$ ' method of detemination -

4. Release of adjacent canopy trees Core \#1, Core \#2, Core \#3, spectes $\underline{s}, \underline{s}$, s

5. Dendrochronology

6. Seedling age

* Categorles surrounded by brackets [ ] are optlonal. ** Direction of fall, if any, from base to top. *k* Lengths in meters. 
GAP DMT

p. 4 of 9

Observers:

G. Stemart, A. Rose

Date $07 / \operatorname{Jan} / 1988$

Site: Rough Greek

Transect nuber: 1 Gap nuber: 1

Adjacent forest: Specles [d.b.h. (cm)] [Distance (m)] [Angle ("E of N)]

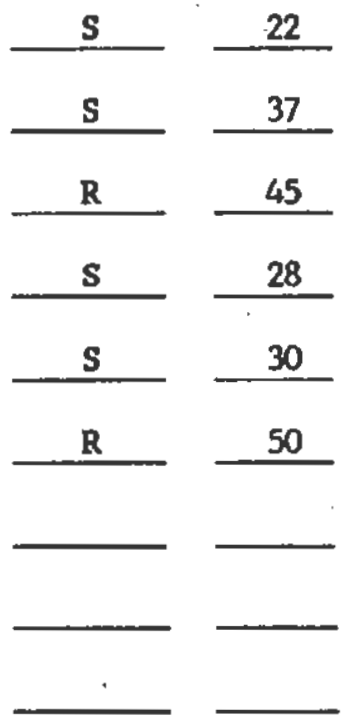

Average canopy helght $25 \mathrm{~m}$ Height to base of cancpy $15 \mathrm{~m}$

Site characterimation: Slope (") $0^{\circ} \quad$ Aspect ( $(\mathrm{E}$ of $\mathrm{N})$ flat

Elevation $520 \mathrm{~m}$ Topographic positian (1-5)*

[Exposure to wind (sibjective)]

[Soil charecterlstics]

[Cep apertare]

* 1 - Valley botton, 2 - Concave lawer slope, 3 - Midslope, 4 - Canvex upper slope, 5 - RIdge or flat uplans. 
Probable replacement trees:

Species d.b.h.(cm) $\underline{H t(\mathbb{m})}$

\begin{tabular}{lll}
$\frac{s}{s}$ & $\frac{21}{18}$ & $\frac{13}{15}$ \\
$\frac{S}{S}$ & $\frac{20}{10}$ & $\frac{23}{14}$ \\
\hline
\end{tabular}

Other Stems: d.b.h. classes (cm)

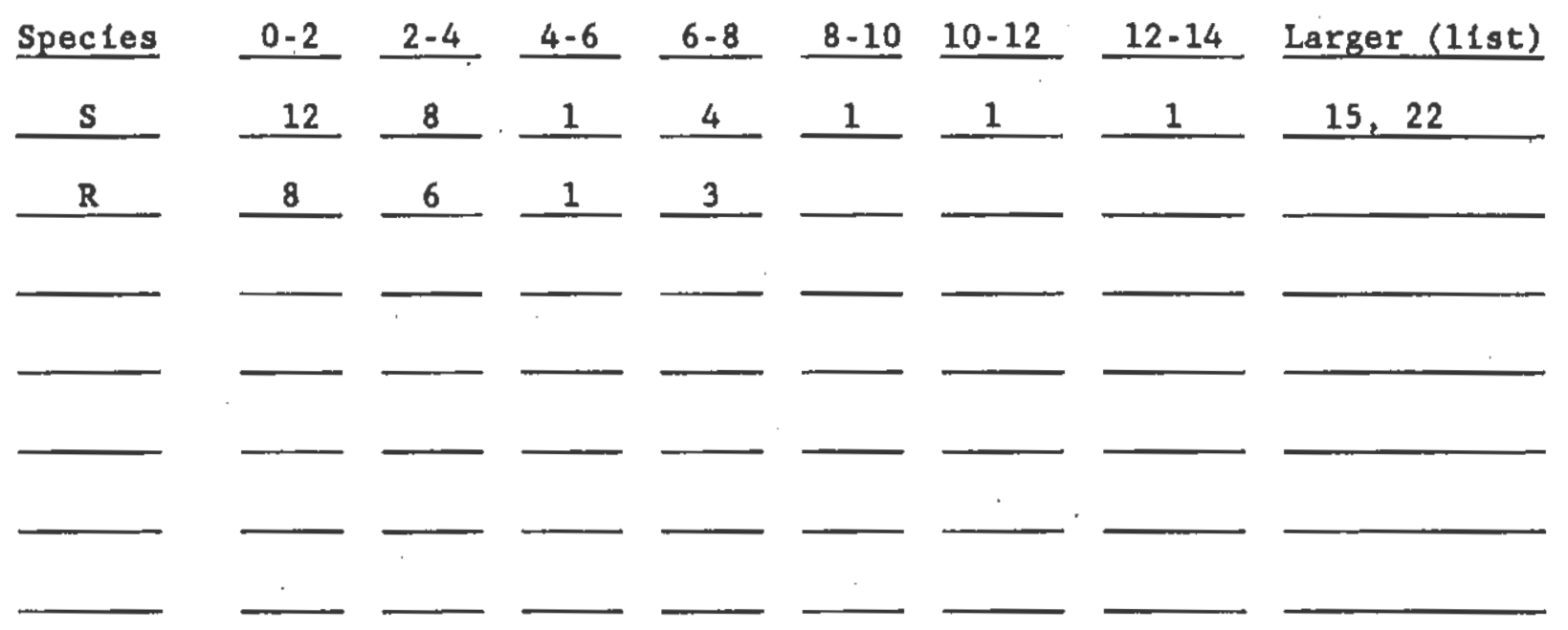

[ht classeg.(四)]

Species 1-3 3-5 5-7 7-9 9-11 11-13 Larger (11st) 
Table 1-(contInued)

CAP DAT

p. 6 of 9

Observers:_C. Stemart, A. Rose Date 07/Jand1988

SIte: Rouph Greek

Transect number: 1 - 1 Gap nmber: 2

Sketch and genecal coments:

[Original Directlankt

Gap makers: Spectes d,b,h. (cm) Ht(m)]* ('E of N) [Agent] Class

$\# 1$
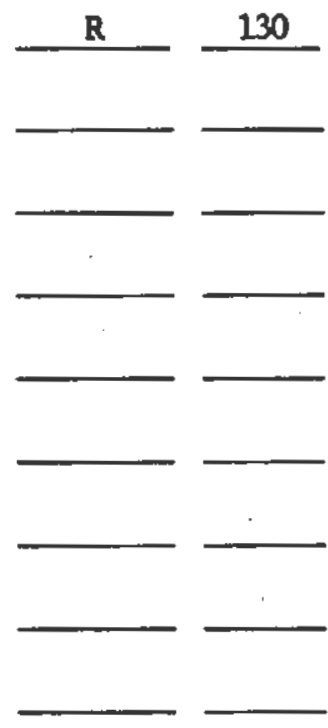

Glasses: 1 - Uprooted; 2 - Partly uprooted; 3 - Broken (stap ht);

4 - Standing dead; 5 - Lfinb deed or broken.

S1ze: Lengths of the segnents in meters, langest first and moving clockwise, or other system (describe).

EG length EG width of length $\infty$ width

1. $21 \quad 2 . \quad 14 \quad 3.11 \quad$ 4. 10

Campass direction of longest segnent $220^{\circ}$

Average helght of dominant seplings in gap 6 m 
Table 1-(contInued)

P. 7 of 9

[Land Classification:*tt] length $x$ width measurements

Total

PAt

Mound

$\log$

Branches

Bark pile

Age: Select firgt avallable method.

1. Gep maker bud or leaf condition old

2. Sapling release ages Core \#3, Core \#4, Core \#5, method of detenrination - bud scales / radial increment.

3. Scars/damage/recovery method of determination -

4. Release of adfacent canopy trees Core \#1, Core \#2, spectes R ${ }^{\prime} \underline{S}^{\prime}$

5. Dendrochronology

6. Seedling age

* Categorles surrounded by brackets [ ] are optlonal.

** Direction of fall, If ary, from base to top.

*t* Lengths in meters. 
Table 1-(continued)

GAP DATA

P. 8 of 9

Observers: G. Stewart, A. Rose

Date $07 / \operatorname{Jan} / 1988$

S1te: Rough Creek

Transect number:

1 Gap muber:

2

Adjacent Forest: Specles [d.b.h.(cm)] [Distance (m)] [Angle ( ${ }^{\circ}$ of N]

\begin{tabular}{cc}
$\mathbf{S}$ & 34 \\
\hline $\mathbf{R}$ & $\frac{35}{4}$ \\
$\frac{\mathbf{R}}{\mathbf{S}}$ & $\frac{41}{50}$ \\
\hline $\mathbf{S}$ & 30 \\
\hline
\end{tabular}

Average canopy height $26 \mathrm{~m}$ Height to base of canopy $18 \mathrm{~m}$ Site characterization: Slope (') $0^{\circ}$ Aspect ('E of M) flat

Elevation 520 m Topogreqhic position (1-5)* 1

[Exposure to wind (subjective)]

[Soil character/stics]

[Cep epertare]

* 1 - Valley bottan, 2 - Concave lower slope, 3 - Midslope, 4 - Camex upper

slope, 5 - Ridge or flat uplans. 


$$
\text { P. } 9 \text { of } 9
$$

Probable replacement trees:

\begin{tabular}{|c|c|c|}
\hline Spectes & $d, b, h \cdot(\mathrm{cm})$ & $\mathrm{Ht}(\mathrm{m})$ \\
\hline $\mathbf{R}$ & 4 & 6 \\
\hline$s$ & 4 & 5 \\
\hline $\mathbf{R}$ & 5 & 6 \\
\hline s & 14 & 7 \\
\hline
\end{tabular}

Other Stems :

d.b.h. classes (cra)

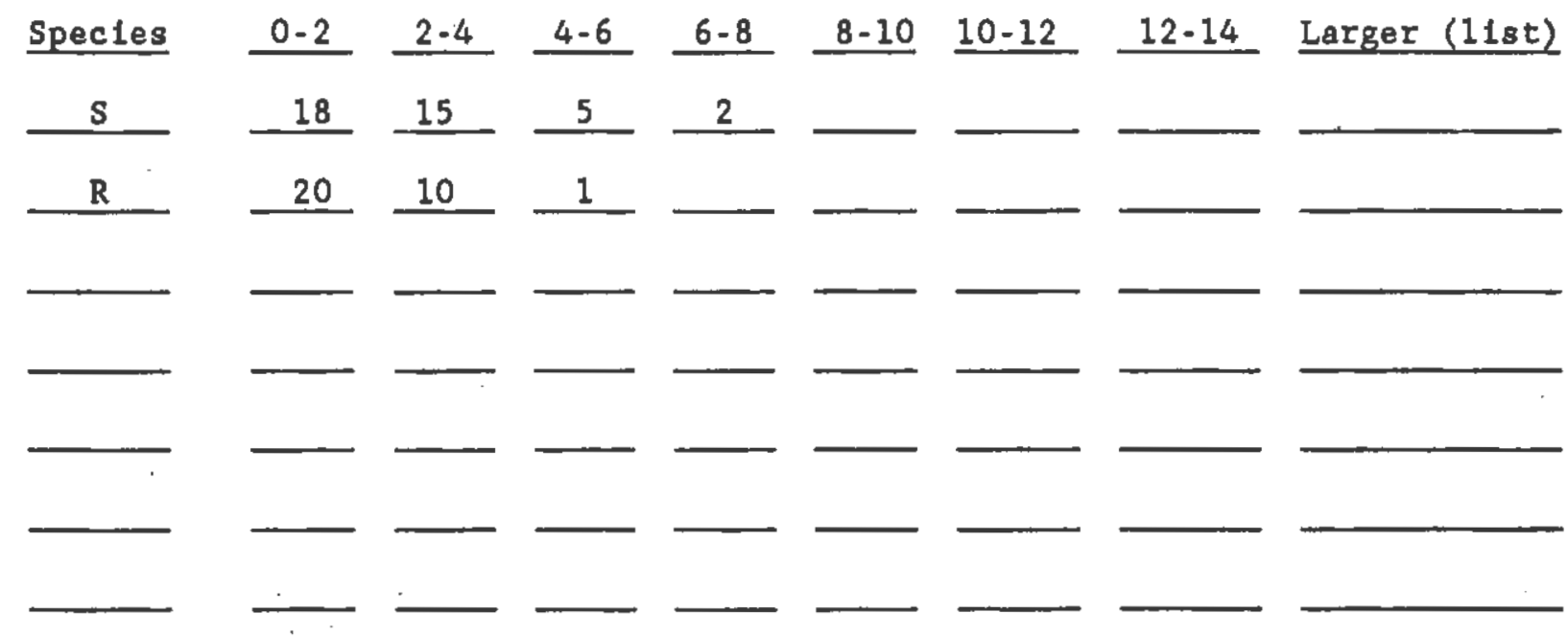

[ht classes (m)]

Species $1-3 \quad 3-5 \quad 5-7 \quad 7-9 \quad 9-11 \quad 11-13$ Larger (11st) 
Acknowledgments

Literature Cited
I thank Jerry Franklin for initiating the series of meetings resulting in this document and to the participants in those meetings who, through discussions and field testing, helped refine the initial suggestions into their present form. Support for some of the antecedent field work these methods were developed from was given by the National Science Foundation (DEB-8214774). Support for the meetings resulting in this document came from a Long Term Ecological Research coordinating grant to J.F. Frankfin. Support for the author to attend the meeting at the Harvard Forest was received from the Wright State University Research Council. Thanks also to T. Spies for his role in managing the publication of this report, $T$. Max for clarifying some of the statistical issues involved in the different sampling procedures, G. Stewart and A. Rose for use of some of their field data, and R.W. Hall for supplying the computer program given in appendix 2.

Barden, Lawrence S. 1979. Tree replacement in small canopy gaps of a Tsuga canadensis forest in the southern Appalachians, Tennessee. Oecologia. 44: 141-142.

Bray, J. Roger. 1956. Gap-phase replacement in a maple-basswood forest. Ecology. 37: $598-600$

Brokaw, Nicholas V.L. 1982. Treefalls: frequency, timing, and consequences. In: Leigh, E.G., Jr.; Rand, A.S.; Windsor, D.M., eds. The ecology of a tropical forest: seasonal rhythms and long-term changes. Washington, DC: Smithsonian Institution Press: 101-108.

Brokaw, Nicholas V.L. 1985. Gap-phase regeneration in a tropical forest. Ecology. 66: 682-687.

Brunig, E.F. 1973. Some further evidence on the amount of damage attributed to lightning and wind-throw in Shorea albida-forest in Sarawak. Commonwealth Forestry Review. 52: 260-265.

Canhan, Charles D.; Denslow, Julle S.; Platt, Willam J. [and others]. 1990. Light regimes beneath closed canopies and tree-fall gaps in temperate and tropical forests. Canadian Journal of Forest Research. 20: 620-631.

Christensen, Norman L.; Franklin, Jerry F. 1987. Small-scale disturbance in forest ecosystems. Bulletin of the Ecological Society of America. 68: 51-53.

Cottam, Grant; Curtis, J.T. 1956. The use of distance measures in phytosociological sampling. Ecology. 37: 451-460.

De Vries, P.G. 1974. Multi-stage line intersect sampling. Forest Science. 20: 129-138

De Vrles, P.G.; Van Eljnsbergen, A.C. 1973. Line intersect sampling over populations of arbitrarily shaped elements. Mededelingen Landbouw Hogeschool 73-19. Wageningen, Netherlands. 21 p.

Ehrenfeld, Joan G. 1980. Understory response to canopy gaps of varying size in a mature oak forest. Bulletin Torrey Botanical Club. 107: 29-41.

Gysel, Leslle W. 1951. Borders and openings of beech-maple woodlands in southern Michigan. Journal of Forestry. 49: 13-19.

Harcombe, P.A.; Marks, P.L. 1983. Five years of tree death in a Fagus-Magnolia forest, southeast Texas. Oecologia. 57: 49-54. 
Horsley, S.B. 1977a. Allelopathic inhibition of black cherry by fern, grass, goldenrod, and aster. Canadian Journal of Forest Research. 7: 205-216.

Horsley, S.B. 1977b. Allelopathic inhibition of black cherry. Il: Inhibition by woodland grass, ferns, and club moss. Canadian Journal of Forest Research. 7: 515-519.

Huenneke, Laura F. 1983. Understory response to gaps caused by the death of Uimus americana in central New York. Bulletin Torrey Botanical Club. 110: 170-175.

Lawton, Robert O.; Putz, Francis E. 1988. Natural disturbance and gap-phase regeneration in a wind-exposed tropical cloud forest. Ecology. 69: 764-777.

Minckler, Mlchael S.; Woerhelde, John D. 1965. Reproduction of hardwoods 10 years after cutting as affected by site and opening size. Journal of Forestry. 63: 103-107.

Moore, Michael R.; Vankat, John L. 1986. Responses of the herb layer to the gap dynamics of a mature beech-maple forest. American Midland Naturalist. 115: 336-347.

Naka, Kazuo. 1982. Community dynamics of evergreen broadleaf forests in southwestern Japan. I: Wind damaged trees and canopy gaps in an evergreen oak forest. Botanical Magazine of Tokyo. 95: 385-399.

Nakashlzuka, Tohru. 1984. Regeneration process of climax beech (Fagus crenata Blume) forests. IV: Gap formation. Japanese Journal of Ecology, 34: 75-85.

Nakashlzuka, Tohru; Numata, Makoto. 1982a. Regeneration process of climax beech forests. I: Structure of a beech forest with the undergrowth of Sasa. Japanese Journal of Ecology. 32: 57-67.

Nakashizuka, Tohru; Numata, Makoto. 1982b. Regeneration process of climax beech forests. II: Structure of a forest under the influences of grazing. Japanese Journal of Ecology. 32: 473-482.

Oldeman, Roelof A.A. 1978. Architecture and energy exchange of dicotyledonous trees in the forest. In: Tomlinson, P.B.; Zimmerman, M.H., eds. Tropical trees as living systems. Cambridge, England: Cambridge University Press: 535-560.

Parker, G.R.; Leopold, D.J.; Elchenberger, J.K. 1985. Tree dynamics in an old-growth, deciduous forest. Forest Ecology and Management. 11:31-57.

PIckford, S.G.; Hazard, J.W. 1978. Simulation studies on line intersect sampling of forest residue. Forest Science. 24: 469-483.

Romme, Willtam H.; MartIn, William H. 1982. Natural disturbance by treefalls in old-growth mixed mesophytic forest: Lilley Cornett Woods, Kentucky. In: Muller, R.N., ed. Central hardwood forest conference 4: Proceedings; [Date of meeting unknown]; [Meeting location unknown]. Lexington, KY: University of Kentucky: 367-383.

Runkle, James R. 1981. Gap regeneration in some old-growth forests of the Eastern United States. Ecology. 62: 1041-1051.

Runkle, James R. 1982. Patterns of disturbance in some old-growth mesic forests of Eastem North America. Ecology. 63: 1533-1546. 
Runkle, James R. 1984. Development of woody vegetation in treefall gaps in a beech-sugar maple forest. Holarctic Ecology. 7: 157-164.

Runkle, James R. 1985. Comparison of methods for determining fraction of land area in treelall gaps. Forest Science. 31: 15-19.

Runkle, James R.; Yetter, Todd C. 1987. Treefalls revisited: gap dynamics in the southern Appalachians. Ecology. 68: 417-424.

Stewart, Glenn H. 1986. Forest development in canopy openings in old-growth Pseudotsuga forests of the western Cascade Range, Oregon. Canadian Journal of Forest Research. 16: 558-568.

Trimble, George R.; Tryon, E.H. 1966. Crown encroachment into openings cut in Appalachian hardwood stands. Journal of Forestry. 64: 104-108.

Tryon, E.H.; Trimble, G.H. 1969. Effect of distance from stand border on height of hardwood reproduction in openings. Proceedings of the West Virginia Academy of Science. 41: 125-133.

Veblen, Thomas T. 1985. Forest development in tree-tall gaps in the temperate rain forest of Chile. National Geographic Research: 162-183.

Watt, A.S. 1947. Pattern and process in the plant community. Journal of Ecology. 35: 1-22.

White, Peter S.; MacKenzle, Mark D.; Busing, Richard T. 1985. Natural disturbance and gap-phase dynamics in southern Appalachian spruce-fir forests. Canadian Journal of Forest Research. 15: 233-240.

Yetter, Todd C.; Runkle, James R. 1986. Height growth rates of canopy trees species in southern Appalachian gaps. Castanea. 51: 157-167. 


\section{Appendix 1}

\section{Partlcipants In Gap} and Related Workshops

\begin{tabular}{|c|c|}
\hline Particlpants ${ }^{\prime}$ & March 1986 \\
\hline Nick Brokaw & - \\
\hline Charles Canham & $x$ \\
\hline Norman Christensen & $x$ \\
\hline Julie Denslow & $x$ \\
\hline Richard Forman & $x$ \\
\hline David Foster & $x$ \\
\hline Jerry Franklin & $x$ \\
\hline Rosine Hall & $\longrightarrow$ \\
\hline David Hibbs & $x$ \\
\hline Ken Lertzman & - \\
\hline Bruce McCune & 一 \\
\hline John Ogden & $x$ \\
\hline Robert Peet & $x$ \\
\hline Steward Pickett & $x$ \\
\hline James Runkle & $x$ \\
\hline Timothy Sipe & $x$ \\
\hline Thomas Spies & $x$ \\
\hline Dennis Whigham & $x$ \\
\hline Peter White & $x$ \\
\hline Gordon Whitney & $x$ \\
\hline
\end{tabular}

${ }^{X} \mathrm{means}$ present; - means absent from the listod workshop.

${ }^{2}$ Because this workshop was related primarily to permanent plat studies, only people who also attended one of the two gap workshops are listed here. 


\section{Appendix 2}

Calculation of Gap Area as a Polygon
The following BASIC program calculates gap area given inputs of azimuth (compass heading) and distance to gap edge. This program calculates positive Cartesian coordinates for each vertex in steps 100-190, and then in steps 200-290 it calculates gap area in square units. If distances are entered in meters, then the units are square meters. This program was written by Rosine W. Hall.

6

DIM A(50),D(50)

DIM $R(50), X(50), Y(50)$

$F 1=0: 52=0$

7

REM input gap data

9

10

20 Input "number of points for this gap?";N

30

For I = 1 to $\mathrm{N}$

Input "azimuth? " $; A(I)$

$40 \quad$ Input "distance? ";D(I)

50 Print

60 Next

$100 \quad$ REM calc cartesian coords

110 For $\mathrm{I}=1$ to $\mathrm{N}$

$120 \quad R=(A(I)-I N T(A(I) / 360) * 360) * 3.1415927 / 180$

130

140

150

160

170

190

200

210

220

230

240

250

260

270

280

290

300
$X(I)=\mathbb{N T}(D(I) * \cos (R) * 100+.5) / 100$

$Y(I)=I N T(D(I) * \operatorname{SIN}(R) * 100+.5) / 100$

If ABS $(X(I))>F 1$ and $X(I)<0$ then $F 1=A B S(X(I))$

If $A B S(Y(I))>F 2$ and $Y(I)<0$ then $F 2=A B S(Y(I))$

Next

REM Calc area

$X(N+1)=X(1)+F 1: Y(N+1)=Y(1)+F 2$

$A R=0$

For $I=1$ TO N

$X(I)=X(I)+F 1: Y(I)=Y(I)+F 2$

Next

For $\mathrm{I}=110 \mathrm{~N}$

$A R=A R+((X(I)+X(I+1)) *(Y(I)-Y(I=1)))$

Next

$\mathrm{AR}=\mathrm{ABS}(\mathrm{AP}) / 2$

Print "area of gap = ";AR

End 


\section{Appendix 3}

Sampling Efficlencies of Belt and Line Transects
The gap protocol described In this report uses a line-intersect technique to locate gaps for further study. As the literature review in this report makes clear, both line and strip transects have been used to sample for gaps. The statistics of both of these techniques have been developed. Another possible technique, which has not been used, Is to use strip transects and sample all gaps found entirely or in part in the transect. This technique, llke the line-intersect technlque, is blased toward oversampling large gaps. In this appendix, a model will be developed to serve two functions: (1) it will provide a way to adjust the size distribution of gaps sampled for sampling bias to estimate the true size distribution of gaps, and (2) it will provlde a way to compare line transects with strip transects of different widths in terms of their relatlve gap-size bias and their relative effects on sample size: wider strips should pick up more small gaps than smaller strips or lines but how many more is not known.

The model will be based on the representation shown In figure 11. The habitat to be sampled has a width $W$. Transect width is $T$. Transects are placed randomly so that their total width is contained within the width of the sultable habitat. Graphically the habitat can be thought to go from $y=0$ to $y=W$, and the transect starting place is randomly chosen from the interval $y=T / 2$ to $y=W-T / 2$.

The probability of encountering a gap along a transect is related to its diameter $D$ (dimension perpendicular to the transect line) and to its position in the habitat: whether it is in the center of the habitat, near the edge, or partly outside. For the model, let the gap start at $y=d_{1}$ and end at $y=d_{2}$, where $d_{2}-d_{1}=D$.

For the following model development, let the expression P (statement) be used to mean the probability that the statement is true. Therefore $P$ (encounter gap of size D) means the probablity that the transect will go through a gap of dimension $\mathrm{D}$. To begin the model, first set,

$$
P D=\int P D R * P R
$$

where

(PD = P (encounter gap of dimension $D)$,

$P D R=P$ (encounter gap of dimension $D$ if it is found in a glven region of the habitat), $P R=P$ (gap occurs in that region of the habitat), and the product of the last two terms are summed over all regions in the habitat.

This step is taken because transects are not equally likely to encounter all gaps of a given diameter. Gaps found near the middle of the habitat will be sampled more often than gaps only partly in the habitat.

Five different regions in the transect will be distingulshed as having different probabilities (fig. 11): (1) where $d_{1}<0$ but $d_{2}>0$, (2) where $d_{1}>0$ but $d_{1}<T$, (3) where $d_{1}>T$ and $d_{2}<W-T$, (4) where $d_{2}>W-T$ but $d_{2}<W$, and (5) where $d_{2}>$ $W$ and $d_{1}<W$. 


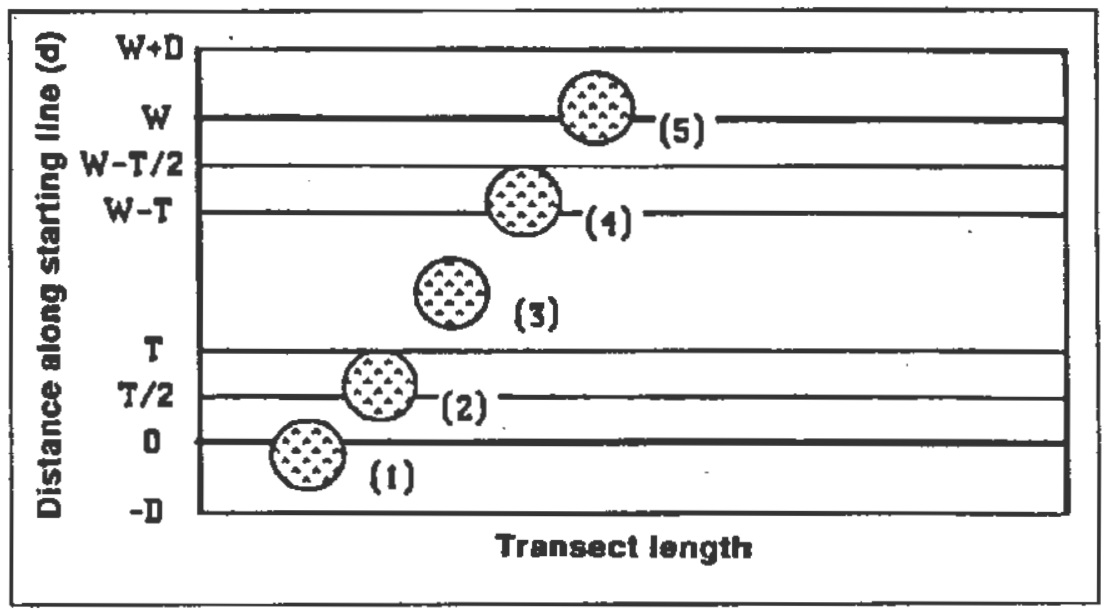

Figure 11-Modal for sampling gaps by using the transect method, where $T=$ transect width, $\mathrm{D}=$ gap dimension perpendicular to the transects, and $W$ is the width of the area to be sampled. Number's reter to the five reglons mentioned in the text. Potential starting positions for the transect are between $D$ and $W$.

Expressions will now be given for the probability that a gap occurs in each region. The denominator, $W+2 D$, represents the width of the tolal location in which a gap of dimension $D$ might occur and still be sampled. The numerators represent the width of each region, as defined above. Note that the sum of these expressions $=1.0$ : all possible gap locations are accounted tor.

$$
\begin{gathered}
P\left(d_{1}<0, d_{2}>0\right)=\frac{D}{W+2 D}, \\
P\left(d_{1}>0, d_{1}<\pi\right)=\frac{T}{W+2 D}, \\
P\left(d_{1}>T, d_{2}<W-\eta\right)=\frac{W-2 T}{W+2 D}, \\
P\left(d_{2}>W-T_{1} d_{2}<W=\frac{T}{W+2 D},\right. \\
P\left(d_{2}>W, d_{1}<W\right)=\frac{D}{W+2 D},
\end{gathered}
$$

The probability of encountering a gap in one of those regions is the fraction of possible transect starting points that start in the region. Here, the denominator is W-T (transects can go from $y=T / 2$ to $y=W-T / 2$ ). The expresslons, region by region, are:

$$
\begin{gathered}
P\left(\text { encounter gap with } d_{1}<0, \alpha_{2}>0\right)=\frac{1}{2}\left(0+\frac{D}{W-T}\right)=\frac{D / 2}{W-T}, \\
P\left(\text { encounter gap with } d_{1}>0, d_{1}<\pi\right)=\frac{1}{2}\left(\frac{D}{W-T}+\frac{D+T}{W-T}\right)=\frac{D+T / 2}{W-T}, \\
P\left(\text { encounter gap with } d_{1}>T, d_{2}<W-T\right)=\frac{D+T}{W-T}, \\
\left.P \text { (encounter gap with } d_{2}>W-T_{1} d_{2}<W\right)=\frac{D+T / 2}{W-T},
\end{gathered}
$$




$$
P \text { (encounter gap with' } d_{2}>W_{1} d_{1}<W=\frac{Q / 2}{W-T} \text {. }
$$

Note that the probabilities are symmetrical, with identical values for regions (1) and (5) and for regions (2) and (4). Also note that because all starting transect locations are equally likely, the probability of encountering a gap in the reglon equals the average of the two extreme probabilities tor that region.

Putting equations (1) through (11) together results in,

$$
P(\text { encounter gap of dimension } D)=\frac{\dot{D}^{2}+W D+W T-T^{2}}{(W+2 D)(W-T)} \text {. }
$$

This equation can be simplified for specific situations. For example, when the sampling area is very large compared to transect widths and typical gap sizes, that is, when $W>D$ and $W>T$, then (12) reduces to:

$$
P(\text { encounter gap of dimension } D)=\frac{W(D+\pi)}{W^{2}}=\frac{D+T}{W} \text {. }
$$

The probability therefore of encountering a gap under the given conditions is proportional to the sum of the gap dimension and the transect width. Further, if a line transect is used,

$$
P \text { (encounter gap of dimension } D)=D / W \text {. }
$$

The probability therefore is proportional to just the gap dimension.

These relations allow one to convert the size distribution of gaps sampled into the size distribution of all gaps by correcting for the sampling bias given above. The general procedure is to relativize the distribution of gaps in the sample so that the total for all classes is 100 percent. Then divide each class by the probabilities from equations

\begin{tabular}{|c|c|c|c|c|c|c|}
\hline \multirow[b]{2}{*}{ Gap area } & \multirow[b]{2}{*}{ Gap diameter } & \multirow{2}{*}{$\begin{array}{l}\text { Observed } \\
\text { frequency } \\
\text { distribution }\end{array}$} & \multicolumn{4}{|c|}{$\begin{array}{l}\text { True frequency } \\
\text { distribution for } \\
\text { transect width (m) }\end{array}$} \\
\hline & & & 0 & 10 & 20 & 30 \\
\hline \multicolumn{7}{|l|}{ Square } \\
\hline Meters & Meters & \multicolumn{5}{|c|}{ Percent $-\cdots-\cdots$} \\
\hline 20 & 5 & 20 & 39 & 28 & 25 & 25 \\
\hline 79 & 10 & 30 & 31 & 33 & 32 & 32 \\
\hline 177 & 15 & 20 & 15 & 18 & 19 & 19 \\
\hline 314 & 20 & 15 & 9 & 12 & 13 & 13 \\
\hline 491 & 25 & 10 & 5 & 7 & 7 & 7 \\
\hline 707 & 30 & 5 & 2 & 3 & 3 & 3 \\
\hline
\end{tabular}
(12), (13), or (14) (whichever is most appropriate) and then rerelativize to 100 percent.

Table 2-Converting an observed size distribution (hypothetlcal) to the true size distribution for width of study area $\mathbf{~} \mathbf{5 0}$ meters 
Table 3-Converting an observed size dlstributlon (hypothetical) to the true slze distribution for width of study area $=1000$ meters

\begin{tabular}{|c|c|c|c|c|c|c|}
\hline \multirow[b]{2}{*}{ Gap area } & \multirow[b]{2}{*}{ Gap diameter } & \multirow{2}{*}{$\begin{array}{l}\text { Observed } \\
\text { frequency } \\
\text { distribution }\end{array}$} & \multicolumn{4}{|c|}{$\begin{array}{l}\text { True frequency } \\
\text { distribution for } \\
\text { transect width }(\mathrm{m})\end{array}$} \\
\hline & & & 0 & 10 & 20 & 30 \\
\hline \multicolumn{7}{|l|}{ Square } \\
\hline Meters & Meters & ---- & Perce & $t--$ & -- & \\
\hline 20 & 5 & 20 & 41 & 29 & 26 & 24 \\
\hline 79 & 10 & 30 & 31 & 33 & 33 & 32 \\
\hline 177 & 15 & 20 & 14 & 18 & 19 & 19 \\
\hline 314 & 20 & 15 & 8 & 11 & 12 & 13 \\
\hline 491 & 25 & 10 & 4 & 6 & 7 & 8 \\
\hline 707 & 30 & 5 & 2 & 3 & 3 & 4 \\
\hline
\end{tabular}

Table 4-Observed slze distributlons resulting from the same true size distribution for width of study area $\mathbf{= 5 0}$ meters

\begin{tabular}{|c|c|c|c|c|c|c|}
\hline \multirow[b]{2}{*}{ Gap area } & \multirow[b]{2}{*}{ Gap diameter } & \multirow{2}{*}{$\begin{array}{l}\text { Observed } \\
\text { frequency } \\
\text { Distribution }\end{array}$} & \multicolumn{4}{|c|}{$\begin{array}{l}\text { True frequency } \\
\text { distribution for } \\
\text { transect width (m) }\end{array}$} \\
\hline & & & 0 . & 10 & 20 & 30 \\
\hline \multicolumn{7}{|l|}{ Square } \\
\hline Meters & Meters & \multicolumn{5}{|c|}{ Percent------ } \\
\hline 20 & 5 & 20 & 8 & 14 & 15 & 15 \\
\hline 79 & 10 & 30 & 23 & 26 & 27 & 27 \\
\hline 177 & 15 & 20 & 22 & 21 & 21 & 21 \\
\hline 314 & 20 & 15 & 21 & 18 & 17 & 17 \\
\hline 491 & 25 & 10 & 17 & 14 & 13 & 13 \\
\hline 707 & 30 & 5 & 10 & 8 & 7 & 7 \\
\hline
\end{tabular}


To demonstrate the results suggested by this procedure, a sertes of simulatlons was done 10 see under which conditions bias is most severe. The first topic addressed is how to interpret the observed size distributions obtained by transects of different widths (table 2). The same observed distribution can be obtained from different true distributions depending on transect width. In general, the wider the transect, the closer the match between observed and true size distributions. Line transects particularly undersample small gaps. On the other hand, bias due to the edges of more narrow study areas does not seem very great: compare the results of tables 2 and 3 where study area width increases 20 -fold with only minor changes in results.

Similar results are obtained by asking how well size distributions obtained by transects of different widths match true distributions (table 4). Again, the wider the transect, the better the match, particularly for very large or very small gaps. Again, the effect of Increasing the width of the study area is negligible (table 5).

Several lessons can be derlved from these simulations. First, the width of the study area is relatively unimportant. Under most circumstances, equatlon (13) or (14) is an adequate estimate of sampling blas: the probability of encountering a gap of dimension $D$ is proportional to the sum of $D$ and transect width $T$. Because the denominator is identical for all gaps, it can be ignored when calculating true size distributions from sample distributlons. The observed percentage values can be divided by $(D+T)$ and rerelativized to obtain the true values.

A second lesson is that wide transects produce a better match to the true distribution than do narrow belt or line transects. In all cases, however, some adjustment of the observed size distribution is necessary so that relative blas alone is an insufficient reason to select strip transects over line transects. Instead it can be argued that wide strip transects should result In an increased sample size of gaps for further study: wide transects should go through more gaps than do line or narrow transects. Table 6 shows increases in the probabilitles of encountering gaps of different sizes for belt transects of different widths, relative to line transects. As expected, wider transects find more gaps than narrow or line transects and the effect is greatest for small gaps. Even 10-meter-wide transects can increase the number of large gaps in the sample by 40 percent. But using line or narrow strip transects will result in proportionally more of the gaps encountered being of the larger sizes more likely to be important for forest regeneration. If those larger gaps are the primary objects of interest, then a wider transect may not be advantageous. A possible compromise could be to use a wide transect but to randomly exclude many of the smaller gaps from more detailed field work. Fleld time could thereby be most profitably employed on the gaps of primary interest and importance.

In conclusion, transect width does make a difference in which gaps are added to the sample set. Size distributions of gaps obtained by using different methods cannot be compared directly, but the bias is both predictable and correctable. Transect width is a variable that can be adjusted according to the specific goals of a particular study and to the specifics of the stand being studied. 
Table 5-Observed size distrlbutions resulting from the same true size distributlon for width of study area $=\mathbf{1 0 0 0}$ meters

\begin{tabular}{|c|c|c|c|c|c|c|}
\hline \multirow[b]{2}{*}{ Gap area } & \multirow[b]{2}{*}{ Gap diameter } & \multirow{2}{*}{$\begin{array}{c}\text { True } \\
\text { frequency } \\
\text { distribution }\end{array}$} & \multicolumn{4}{|c|}{$\begin{array}{l}\text { Observed frequency } \\
\text { distribution for } \\
\text { transect width (m) }\end{array}$} \\
\hline & & & 0 & 10 & 0 & 30 \\
\hline $\begin{array}{l}\text { Square } \\
\text { Moters }\end{array}$ & Meters & --- & Perce & $t--$ & --- & -- \\
\hline $\begin{array}{l}20 \\
79 \\
177 \\
314 \\
491 \\
707\end{array}$ & $\begin{array}{c}5 \\
10 \\
15 \\
20 \\
25 \\
30\end{array}$ & $\begin{array}{c}20 \\
30 \\
20 \\
15 \\
10 \\
5\end{array}$ & $\begin{array}{r}7 \\
22 \\
21 \\
21 \\
18 \\
11\end{array}$ & $\begin{array}{r}13 \\
25 \\
21 \\
19 \\
14 \\
8\end{array}$ & $\begin{array}{r}15 \\
27 \\
21 \\
18 \\
13 \\
7\end{array}$ & $\begin{array}{r}16 \\
27 \\
20 \\
17 \\
12 \\
7\end{array}$ \\
\hline
\end{tabular}

Table 6-Increased sample size resulting from increased belt width for width of study area = 100 meters, by using equation (12)

Increased probability of finding gaps relative to line transects for transects of width (m)

\begin{tabular}{lcccc}
$\begin{array}{l}\text { Gap } \\
\text { area }\end{array}$ & $\begin{array}{c}\text { Gap } \\
\text { diameter }\end{array}$ & 10 & 20 & 30 \\
\hline $\begin{array}{l}\text { Square } \\
\text { Meters }\end{array}$ & Meters & & & \\
& & & & \\
20 & 5 & 3.0 & 5.1 & 7.1 \\
79 & 10 & 2.0 & 3.1 & 4.2 \\
177 & 15 & 1.7 & 2.4 & 3.2 \\
314 & 20 & 1.5 & 2.1 & 2.7 \\
491 & 25 & 1.4 & 1.9 & 2.4 \\
707 & 30 & 1.4 & 1.8 & 2.2 \\
\hline
\end{tabular}


Appendix 4

Blank Data Forms

TRANSECT DATA

p. 1 of 5

Observers :

Date

19

S1te :

Transect number: Long 1tude :

Lat L tude:

Inltial compass bearing corrected for declination:

Starting location description:

Distance* Observat1on** D1stance Observation Distance Observation

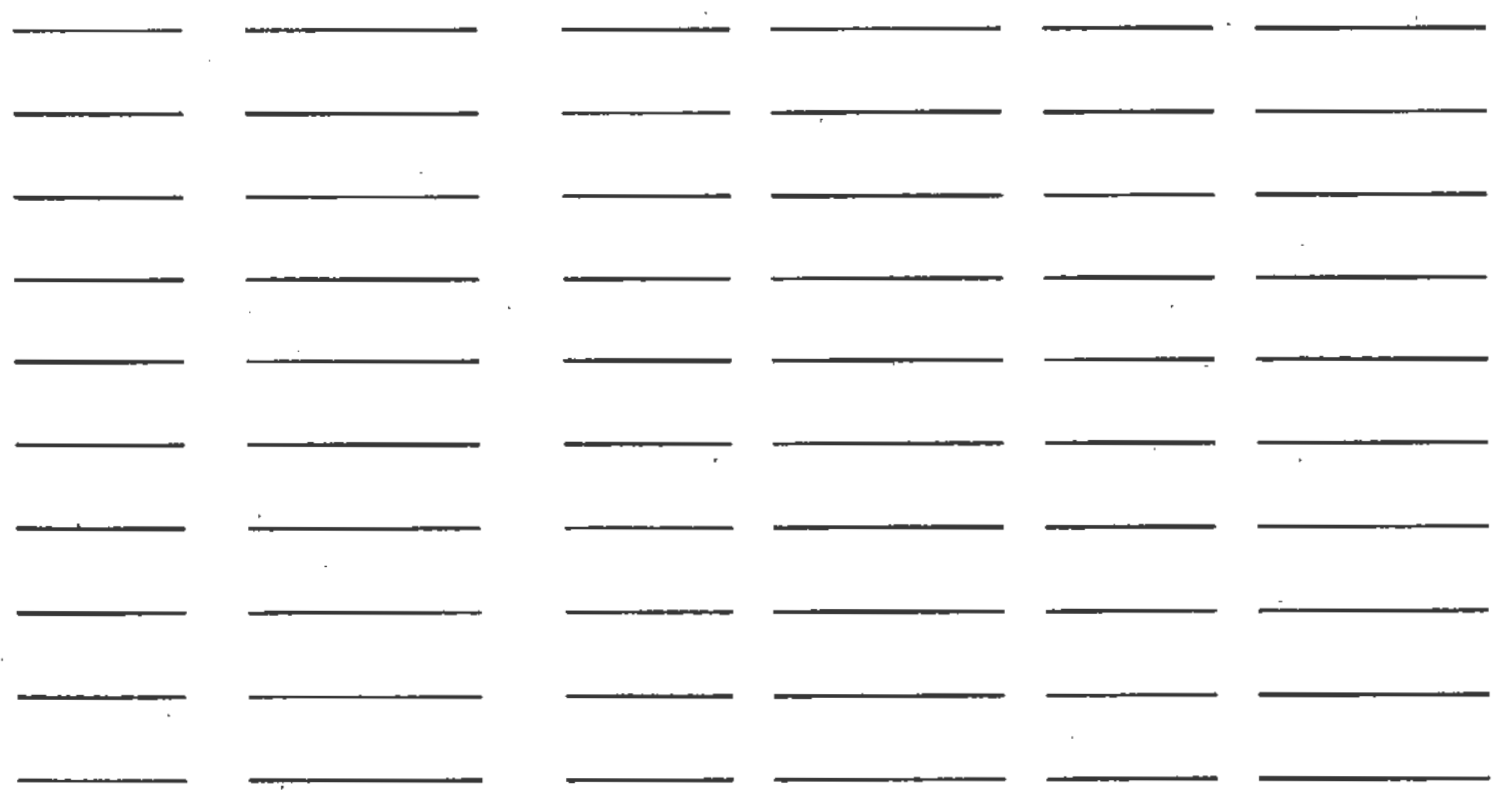

* In meters from starting position, using a tape.

** For example, Start gap, end gap, tra1ls, fallen loga, streams, change. compass direction, establish a point-centered quarter polnt, etc. 


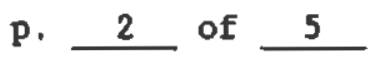

Observers :

Date : 19

Site:

Transect number:

Gap number:

sketch and general comments:

\section{COriginal Direction**}

Gap makers: Specles d.b.h.(cm) Ht(m)]* ("E of N) [Agent] Class

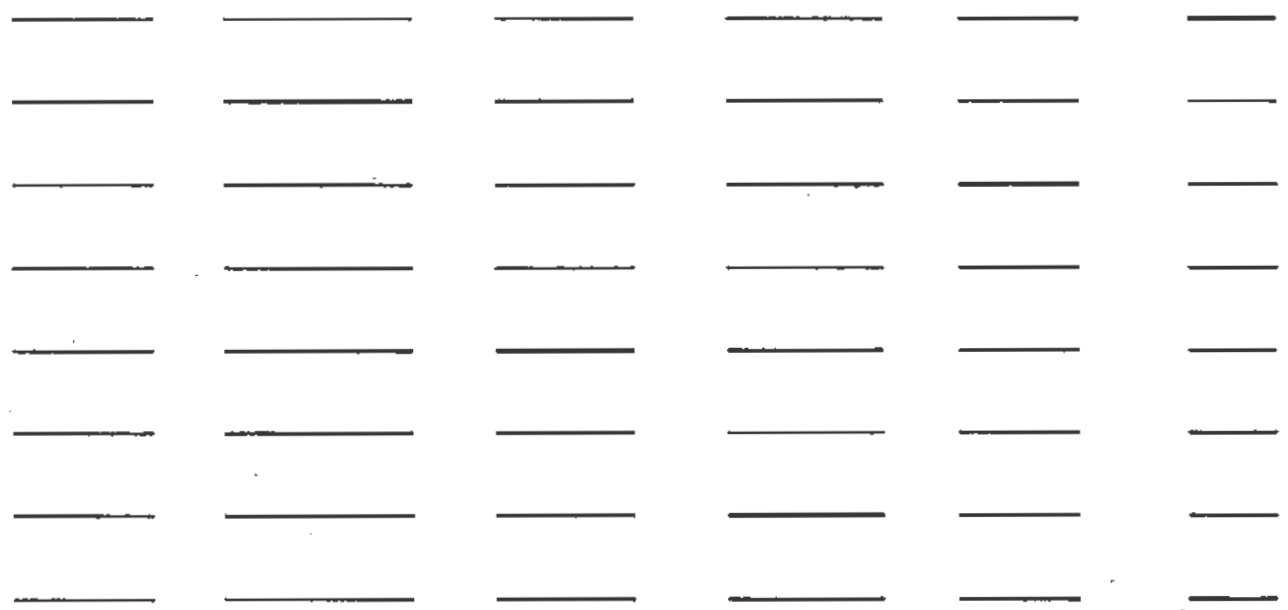

Classes: 1 - Uproted; 2 - Partly uprooted; 3 - Broken (stum ht); 4 - Standing dead; 5 = Linb dead or broken.

Size: Lengths of line segnents in meters, longest first and movlng clockalse, or other systen (describe).

1.

2.

3.

4.

Compass direction of longest segment

Average height of daminant saplings in gap 
p. 3 of 5

[Land Classification:*k*) length $x$ width measurements

Total

PIt

Nound

$\log$

Branches

Bark pile

Age: Select first avallable method.

1. Gap maker bud or leaf condition

2. Sapling release ages $\longrightarrow$ ' ' method of datermination - bud scales / radtal increment.

3. Scars/dimage/recovery method of detemination -

4. Release of adjacent canopy trees specles

5. Dentrochronology

6. Seedling age

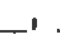
, $-$

* Categorles surrounded by brackets [ ] are optional.

* Direction of fall, If any, fram base to top. *k* Lengths in meters. 


$$
\text { P. } 4 \text { of } 5
$$

Observers :

Date : 119

Site:

Transect number:

Gap number:

Adjacent forest: Species [d.b.h.(cm)] [Distance (m)] [Angle ("E of N)]

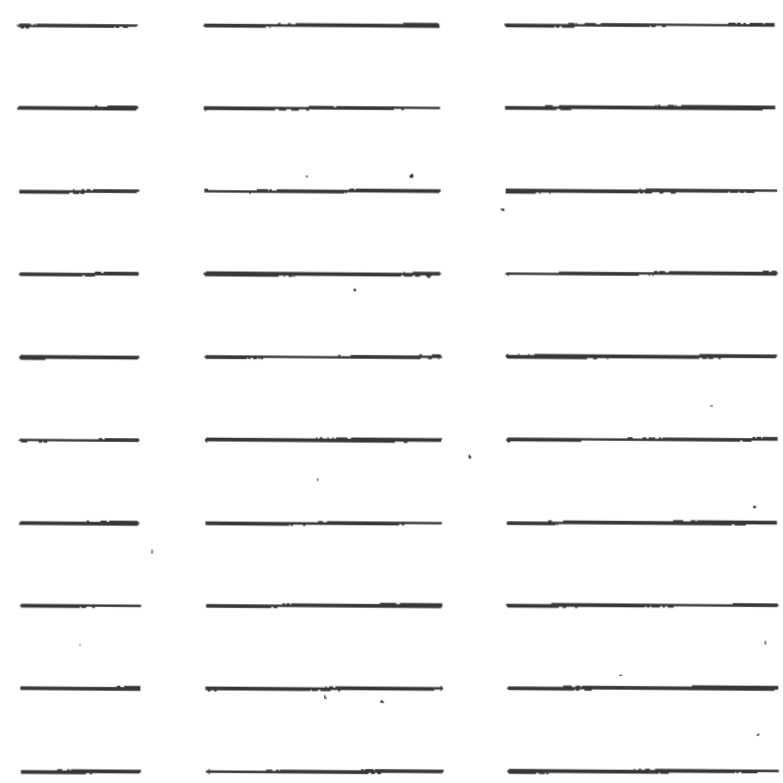

Average canopy helght

Helght to base of canopy

Site characterlzation: Slope (")

Aspect ( $\mathrm{E}$ of $\mathrm{N})$

Elevation Topographic position (1-5)*

[Exposure to wind (subjective)]

[Soll characterfstics]

[Gep apertare]

* 1 - Valley bottan, 2 - Concave lower slope, 3 - Midslope, 4 - Convex uper slope, 5 - RIdge or flat uplands. 


$$
\text { p. } 5 \text { of } 5
$$

Probable replacement trees:

$$
\text { Specles d.b.h.(mil) } \underline{H t(m)}
$$

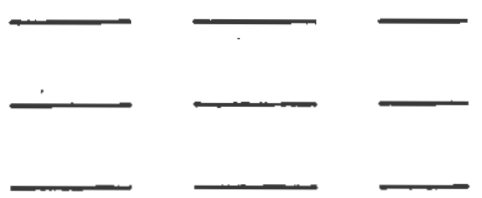

Other Stems:

d.b.h. classes (cm)

Specieg

$\underline{0-2} \underline{2-4} \quad \underline{4-6} \quad \underline{6-8} \quad \underline{8-10} \quad \underline{10-12} \underline{12-14} \underline{\text { Larger (1ist) }}$
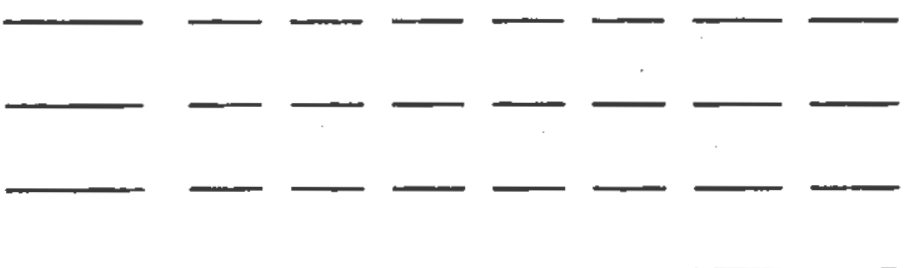

[ht classes (m)]

Spectes $\quad 1-3 \quad 3-5 \quad 5-7 \quad 7-9 \quad 9-11 \quad \underline{11-13}$ Larger (11st)

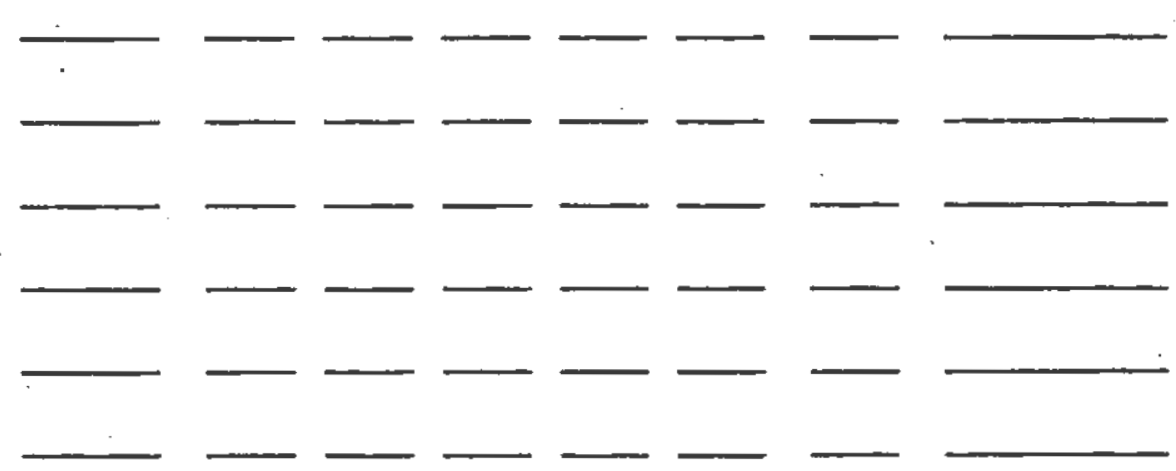


Runkle, James R. 1992, Guidelines and sample protocol for sampling forest gaps. Gen. Tech. Rep. PNW-GTR-283. Portland, OA: U.S. Department of Agriculture, Forest

Service, Pacific Northwest Research Station. 44 p.

Comparative studies of forest structure and dynamics require standardized methods. A prolocol for sampling lorest canopy gaps is presented. Methods used in published gap studies are reviewed. The sample protocol will be useful in developing a broader understanding of forest structure and dynamics through comparative studies across different forest ecosystems.

Keywords: Forest structure, forest canopies, gap dynamics, heterogeneity, natural disturbance.

The Forest Service of the U.S. Department of Agriculture is dedicated to the principle of multiple use management of the Nation's forest resources for sustained yields of wood, water, forage, wildlife, and recreation. Through forestry research, cooperation with the States and private forest owners, and management of the National Forests and National Grasslands, it strives-as directed by Congress-to provide increasingly greater service to a growing Nation.

The U.S. Department of Agriculture is an Equal Opportunity Employer. Applicants for all Department programs will be given equal consideration without regard to age, race, color, sex, religion, or national origin.

Pacific Northwest Research Station 333 S.W. First Avenue

P.O. Box 3890

Portland, Oregon 97208-3890 